\title{
LOS MECANISMOS DE JUSTICIA ALTERNATIVOS COMO POLÍTICA DE JUSTICIA COTIDIANA ANTE EL CONFLICTO POR EL USO DEL AGUA EN MÉXICO Y SU POTENCIAL APLICACIÓN EN EL PERÚ
}

\section{ALTERNATIVE JUSTICE MECHANISMS AS A DAILY JUSTICE POLICY IN THE FACE OF THE CONFLICT OVER THE USE OF WATER IN MEXICO AND ITS POTENTIAL APPLICATION IN PERU}

\author{
Arnulfo Sánchez García \\ Profesor Titular de Derecho \\ Universidad Autónoma de Nuevo León \\ arnulfosanchezgarcia@hotmail.com \\ México, Nuevo León \\ Borja García Vázquez \\ Profesor de Derecho \\ Universidad Autónoma de Nuevo León \\ borjagarcia131@gmail.com \\ Nuevo León, México
}

\section{SUMARIO}

- Introducción

- Análisis contextual de la producción de plata y disponibilidad de recursos hídricos en México y Perú

- El conflicto hídrico-minero en el ámbito local

- Los organismos de cuenca y la intervención de los usuarios de agua a través de una política nacional de aplicación de mecanismos alternativos de solución de controversias

- La problemática generada en el contexto de los MASC

- Conclusiones y propuestas

\section{ÍNDICE DE TABLAS}

- Tabla $N^{\circ} 1$ - Evolución mundial del suministro y precio de la plata entre 2008 y 2017

- Tabla $N^{\circ} 2$ - Evolución de la producción anual y reservas de plata en México y Perú (en toneladas).

- Tabla $N^{\circ} 3$ - Evolución del precio de las exportaciones de plata en México y Perú, entre 2005 y 2016.
- Tabla $\mathrm{N}^{\circ} 4$ - Evolución del precio de las exportaciones de arroz, frijoles y maíz en México y Perú, entre 2005 y 2016.

- Tabla N ${ }^{\circ} 5$ - Relación de cantidad existente de agua renovable y población por Estado en el año 2015.

- Tabla $N^{\circ} 6$ - Relación por Estados entre el agua renovable per cápita en 2015 y la aportación al PIB nacional en 2014

- Tabla N $\mathrm{N}^{\circ} 7$ - Relación de cantidad existente de agua renovable y población por vertiente en Perú

- Tabla $N^{\circ} 8$ - Comparativa del agua renovable per cápita de las tres regiones hidrológicas-administrativas que convergen en el Estado de Zacatecas, su promedio, y la media nacional.

- Tabla No 9 - Comparativa del agua disponible en las Cuencas de los ríos Ene, Mantaro, Perené, y Tambo, en hm3, en el año 2011 .

\section{RESUMEN}

Los dos principales países productores de mineral de plata en el mundo, México y Perú, comparten una situación donde convergen la disparidad en la disponibilidad de agua 
por regiones, junto a la conflictividad que generan sus explotaciones mineras. Por ser la plata el elemento que muestra la similitud entre los espacios de estudio del presente trabajo, se han seleccionado las principales regiones con mayor volumen de producción de plata de ambos países, el Estado de Zacatecas y el departamento de Junín, para analizar la problemática existente por el uso de los recursos hídricos entre las compañías mineras y las poblaciones adyacentes, y cómo la intervención de los mecanismos de justicia alternativos pueden materializarse en una política de justicia cotidiana que dé solución a estos conflictos.

\section{ABSTRACT}

The two main countries producers of silver ore in the world, Mexico and Peru, share a situation of disparity in the availability of water by regions, together with the conflict generated by their mining operations. silver is the element that shows the similarity between the study spaces of this work, the main regions with the highest volume of silver production in both countries, the State of Zacatecas and the department of Junín, have been selected to analyze the existing problems due to the use of water resources between mining companies and adjacent populations, and how the intervention of alternative justice mechanisms can be materialized in a daily justice policy that resolves these conflicts.

\section{PALABRAS CLAVE}

Conflicto por el agua; conflicto minero; conflicto social; escasez hídrica; minería de plata; mecanismos alternativos de solución de conflictos.

\section{KEYWORDS}

Conflict over water; mining conflict; mechanisms of alternative dispute resolution; silver mining; social conflict; water scarcity.

\section{INTRODUCCIÓN}

La minería representa una de las principales actividades para la economía de México y Perú, llevando aparejada una conflictividad como consecuencia del uso de grandes volúmenes de agua, que afecta a las poblaciones anexas a los centros de explotación minera.

En este contexto existe una desigualdad de fuerzas negociadoras respecto del uso al que se destina el agua, entre las poblaciones afectadas y las entidades de explotación mineras, ante lo cual, los tribunales judiciales se encuentran desbordados por la complejidad y la especialización técnica de los temas a tratar, así como por el excesivo volumen de trabajo con que ya cuentan, y la incapacidad material de impartir justicia en un plazo de tiempo razonable. Por ello, estudiamos la viabilidad en la aplicación de los métodos alternativos de solución de controversias (MASC), mediante la descripción de la situación existente en México y Perú, identificando las políticas públicas que se han desarrollado para atender la problemática descrita, en el marco de la denominada iniciativa de Justicia cotidiana.

\section{ANÁLISIS CONTEXTUAL DE LA PRODUCCIÓN DE PLATA Y DISPONIBILIDAD DE RECURSOS HÍDRICOS EN MÉXICO Y PERÚ}

México es el $14^{\circ}$ país más grande del mundo, con una población superior a 123 millones de personas (de las cuales una cuarta parte vive alrededor de la Ciudad de México), su clima que varía del tropical al desértico (Central Intelligence Agency, 2017a), registra una precipitación media anual, que en 2016 fue de $744,1 \mathrm{~mm}$, pero desigual si se comparan las regiones del norte y del sur del país (sirva de ejemplo la precipitación media en el Estado de Baja California, de $219 \mathrm{~mm}$, frente a los 1.781 $\mathrm{mm}$ ) del Estado de Morelos (Comisión Nacional del Agua, 2017); y de acuerdo con estimaciones de 2016, un Producto Interior Bruto (PIB) en el que la agricultura representa el 3,7\%, la industria el 33,1\%, y el sector servicios supone el 63,2\% (Central Intelligence Agency, 2017a).

Perú ocupa el puesto $20^{\circ}$ de los países en función de su extensión, contando con una población superior a 30 millones de personas (un tercio del cual vive en la zona oeste del país, principalmente en Lima), su clima que varía del seco en el oeste, al templado y frío en los Andes, o al tropical en el este (Central Intelligent Agency, 2017b), registra una precipitación media anual en el año 2015 de $897 \mathrm{~mm}$, y al igual que en el caso de México, con 
Alternative justice mechanisms as a daily justice policy in the face of the conflict over the use of water in Mexico and its potential application in Peru

diferencias entre regiones, como ejemplifica la media anual de $5,5 \mathrm{~mm}$ del departamento de Ica, frente a los $3282,2 \mathrm{~mm}$ del departamento de Loreto (Instituto Nacional de Estadística e Informática, 2017). Conforme a estimaciones de 2016, el PIB de Perú era representado, de acuerdo con su sector, de la manera siguiente: un $7,3 \%$ procedente de la agricultura; el $34,2 \%$ de la industria; y el 58,5\% del sector servicios (Central Intelligent Agency, 2017b).

Como se puede ver, ambos países tienen marcadas diferencias demográficas y climáticas, a pesar de lo cual, cuentan con un punto coincidente y relevante para el presente estudio: la producción de plata. Este metal precioso, al igual que el oro, constituye un valor refugio. Como expresa Razeto M. (2008) ante un supuesto de crisis financiera, como la ocurrida en 2008 , crece la insolvencia, y con ella aumenta la desconfianza de los inversores $\mathrm{y}$ tenedores de acciones, bonos y títulos, quienes buscan refugio en activos con mayor seguridad, como son el oro y la plata, por tener un valor en sí mismo. Concretamente, en septiembre de 2008, en solo dos días, la Bolsa mercantil de Nueva York vio como el precio del oro se incrementó en un 14\% (hasta alcanzar los 891,5 dólares por onza) y un $20 \%$ en el caso de la plata (logrando un valor de 12,68 dólares por onza) (El País, 2008).

Tabla $N^{\circ} 1$ - Evolución mundial del suministro y precio de la plata entre 2008 y 2017

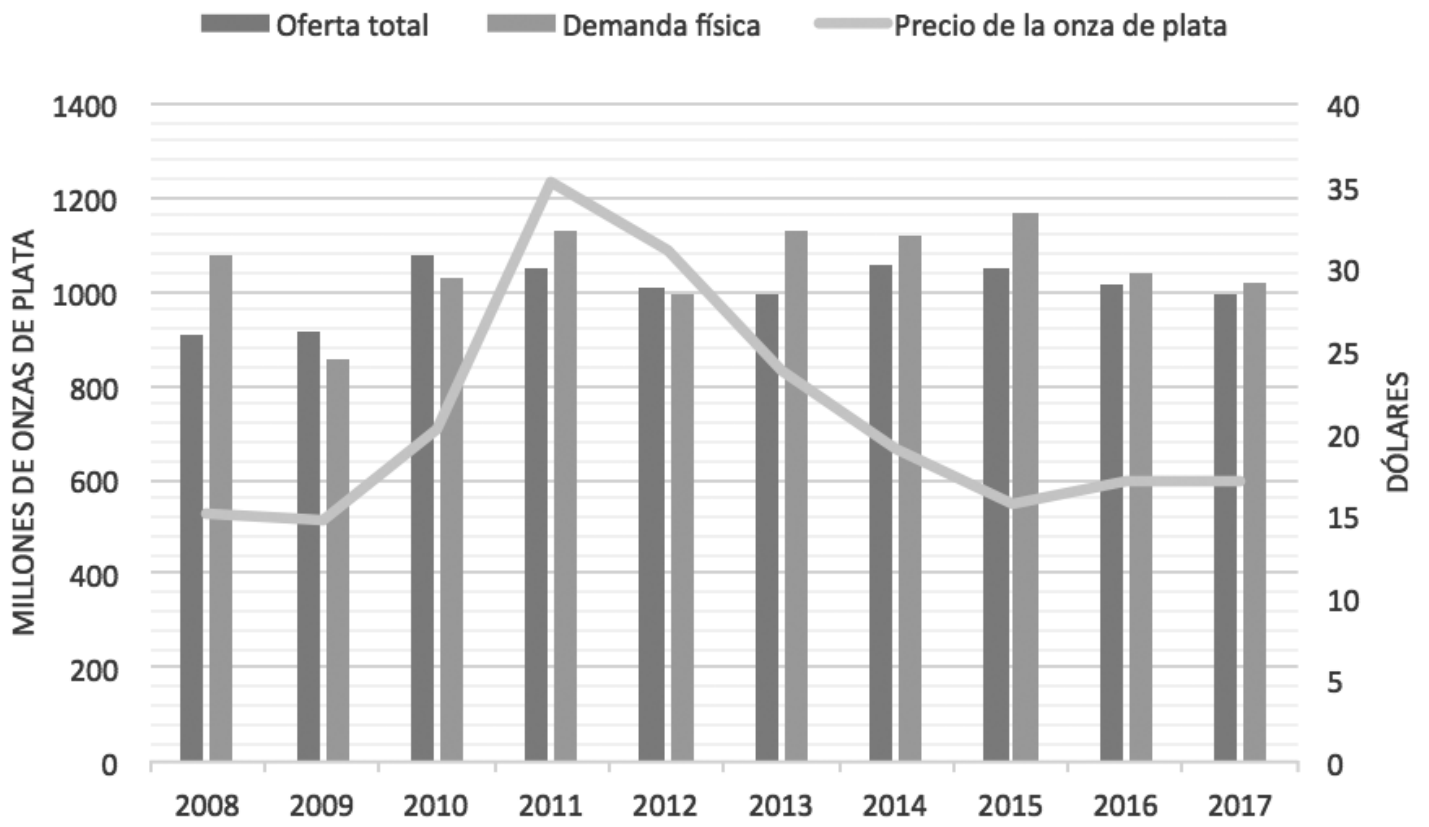

Fuente: The Silver Institute - World Silver Survey 2018

Elaboración: Propia

Debemos indicar, de acuerdo con Cervera Fantoni (2003) que la "onza troy", que es la unidad de medida empleada en el peso de los metales preciosos, equivale a 31,103 gramos. La plata constituye un bien refugio, como se aprecia atendiendo a la evolución experimentada desde la crisis de 2008 , que hizo que sobrepasase el doble de su valor original, descendiendo a partir de 2011 hasta retornar a valores cercanos al comienzo de la crisis. Es un elemento de interés económico para los países que cuentan con reservas del mismo, no solo por los usos a que se puede destinar, sino por su valor esencial ante escenarios que requieren garantizar la solvencia de los sujetos. 
La explotación de este mineral se da principalmente en dos países, México y Perú, pero dada la extensión geográfica de los mismos, debe concretarse que las minas desde las que se extrae el recurso, están ubicadas en regiones concretas, por lo que nos centraremos en los principales departamentos productores.

De acuerdo con información del Servicio Geológico de los Estados Unidos de América, México es el principal productor mundial de plata desde el año 2010, en el que superó a Perú, con una producción media anual de 4326 toneladas $^{1}$. De la cantidad total de plata producida en México, el 46\% de la producción corresponde al Estado de Zacatecas, con una media anual de plata extraída de 2339 toneladas ${ }^{2}$, siendo el primer productor nacional (Gobierno del Estado de Zacatecas, 2013) comprendiendo un valor de 19919 millones de pesos mexicanos solo la extracción de plata en el ejercicio de 2015 (Servicio Geológico Mexicano, 2016). Por su parte, en el caso de Perú, las tres primeras regiones productoras de plata son Junín, representando el $20 \%$ de la producción estatal de plata ( 881 toneladas al año), Lima, con el 18\% (791 toneladas al año) y Áncash, con el 18\% (785 toneladas anuales) (Sociedad Nacional de minería, petróleo y energía, 2017).

Tabla $N^{\circ} 2$ - Evolución de la producción anual y reservas de plata en México y Perú (en toneladas).

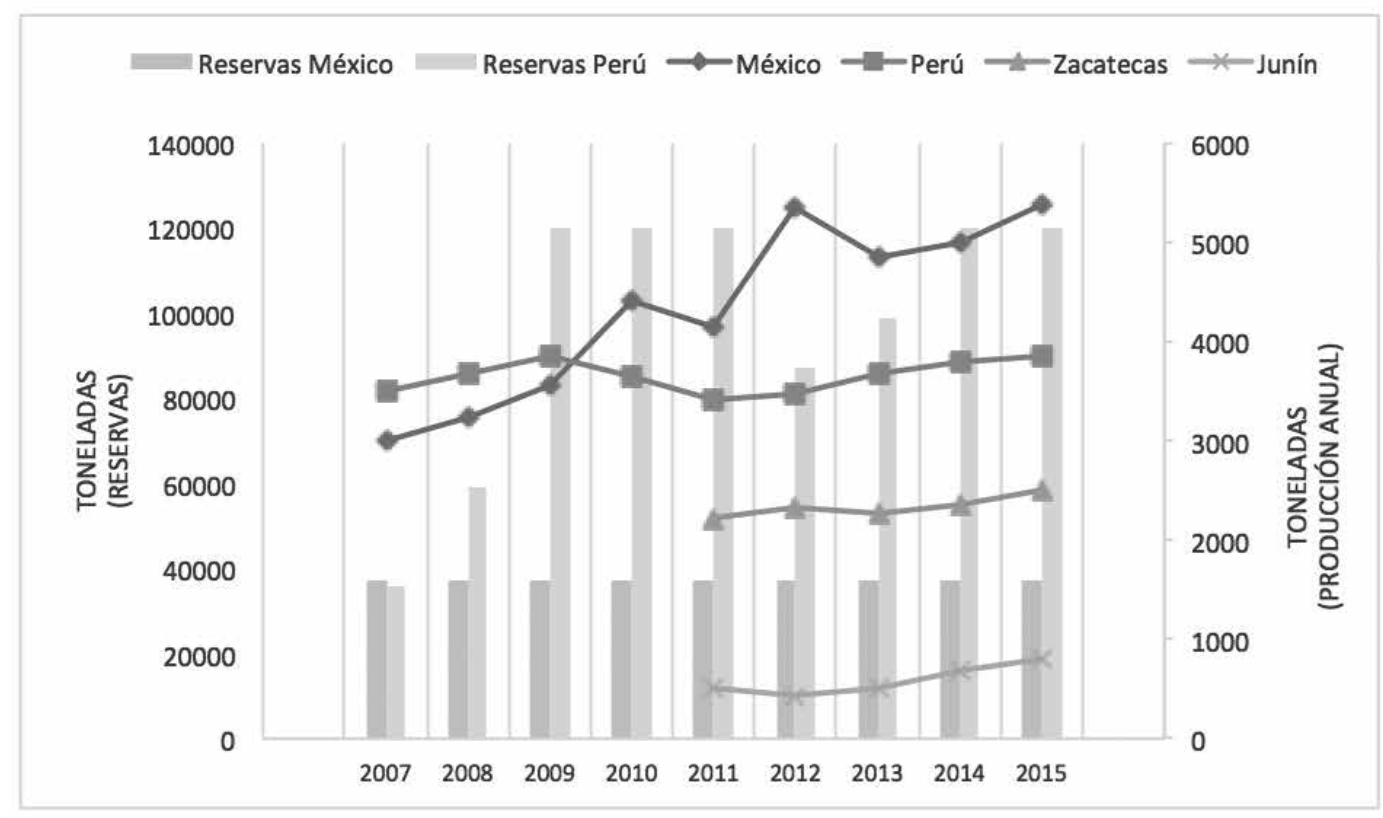

Fuente: informes del Servicio Geológico de los Estados Unidos (USGS) "Mineral commodity summaries" correspondientes a los años 2009 a 2017; el documento del Servicio Geológico Mexicano "Panorama Minero del Estado de Zacatecas" de diciembre de 2016; y los informes de la Sociedad Nacional de mineria, petróleo y energía "Reporte Estadístico Mineroenergético" correspondientes a los años 2011-2015.

Elaboración: Propia

\footnotetext{
1 Cálculo realizado conforme a los datos Servicio Geológico de los Estados Unidos de Norte América, de la producción obtenida por México en el periodo comprendido entre los años 2007 y 2015. United States Departament of the Interior \& United States Geological Survey.

2 Cálculo realizado a partir de la información contenida en el documento del Servicio Geológico Mexicano "Panorama Minero del Estado de Zacatecas" de diciembre de 2016.
} 

el conflicto por el uso del agua en México y su potencial aplicación en el Perú

Alternative justice mechanisms as a daily justice policy in the face of the conflict over the use of water in Mexico and its potential application in Peru

El 30 de diciembre de 2015 el estado de Zacatecas contaba con un total de 2410 concesiones mineras (Servicio Geológico Mexicano, 2016), incluida la mina de Fresnillo, abierta en el año 1554 y considerada la mayor mina de plata del mundo (Morales, 2015). Por su parte, Junín en el año 2016 contaba con 871068,8 hectáreas de concesiones mineras, es decir, el 23,1\% de su territorio (CooperAccion, 2016), existiendo datos que constataban la presencia en 2014, de alrededor de 2500 mineras artesanales sin formalizar (Atencio, 2014).

Este metal, y su industria asociada, representa un importante elemento receptor de capitales e inversión extranjera. En el caso de México y Perú, los dos principales productores de Norteamérica y Sudamérica, la evolución de sus exportaciones ha sido la siguiente:

Tabla N 3 - Evolución del precio de las exportaciones de plata en México y Perú, entre 2005 y 2016.

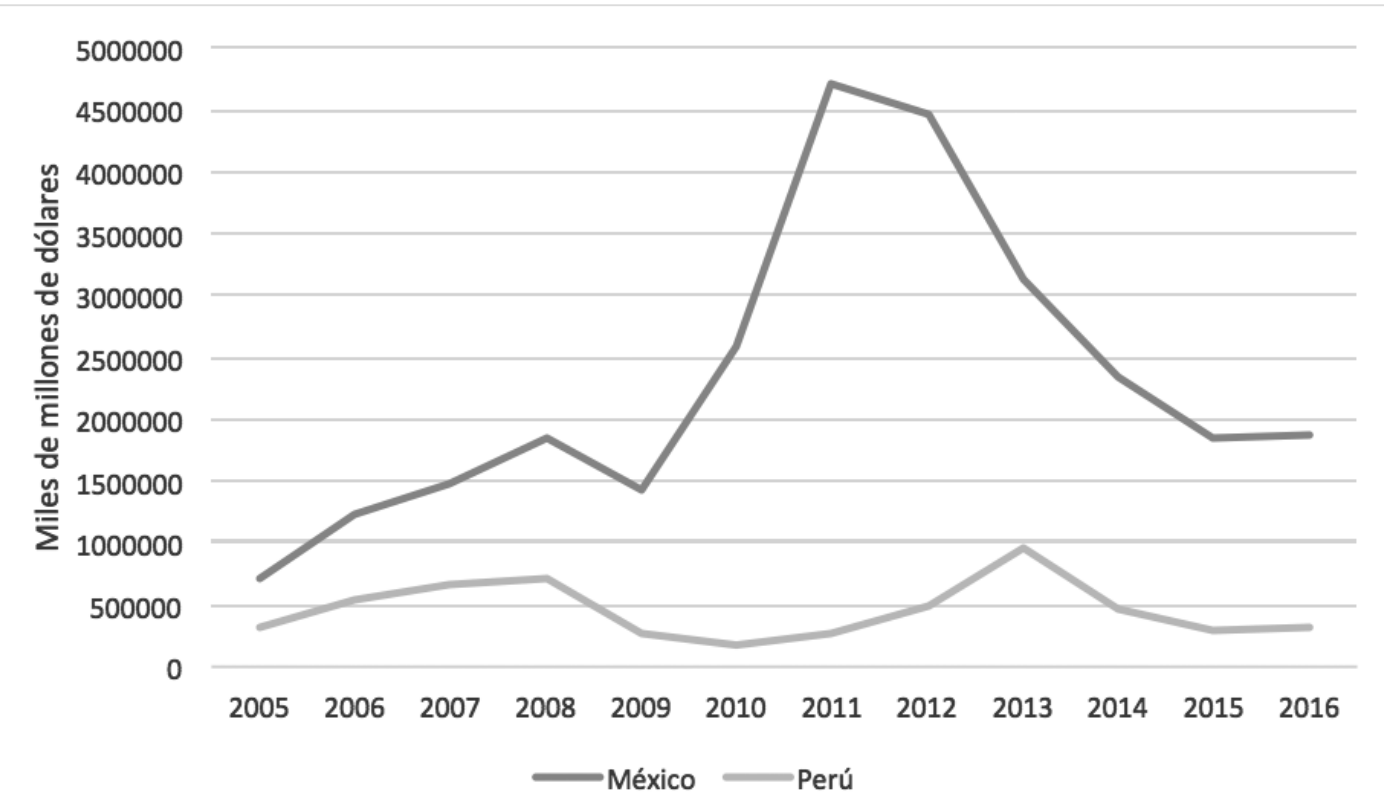

Fuente: Información de The Observatory of Economic Complexity Elaboración: Propia

Junto a la actividad minera, la agricultura supone el principal sector productivo de la mayoría de los municipios del estado de Zacatecas (Gobierno del Estado de Zacatecas, 2013), pese a que las tres cuartas partes del territorio zacatecano son zonas áridas y semiáridas, y donde solo el $14 \%$ cuenta con características adecuadas para las labores agrícolas (Servicio Geológico Mexicano, 2016). Las actividades agrícolas en Zacatecas ocupan una extensión equivalente al $6 \%$ de la superficie cultivada de la República Mexicana (Gobierno del Estado de Zacatecas, 2013), comprendiendo su producción en el ejercicio de 2016, un valor de 16647 millones de pesos (Servicio de Información Agroalimentaria y Pesquera, 2017).

A 31 de diciembre de 2014, Zacatecas contaba con 770 núcleos agrarios, de los cuales 755 eran ejidos y los 15 restantes eran comunidades (Registro Agrario Nacional, 2014), lo que representa el $2,40 \%$ de los 31992 núcleos agrarios con que contaba todo el país en esa fecha (29618 ejidos y 2374 comunidades) (Registro Agrario Nacional, 2014). En Zacatecas, solo el $12,7 \%$ de la superficie cultivada cuenta con riego debido 
a la escasez existente de agua en la mayor parte del territorio del estado (Gobierno del Estado de Zacatecas, 2013), con $2454 \mathrm{~m} 3$ por habitante al año, siendo una cantidad inferior al promedio del total de la República, cifrado en $3692 \mathrm{~m}^{3}$ por habitante al año (Comisión Nacional del Agua, 2016). Mientras, en Perú, en la región de Junín, para el año 2015 los datos oficiales sitúan el valor de la producción agrícola en 16897298 de nuevos soles; y de las 465880,4 hectáreas de superficie agrícola, solo el 13,31\% cuenta con riego (Gobierno Regional Junín, 2017).

Algunos productos agrícolas, como son el arroz, los frijoles y el maíz, son vitales para las poblaciones de México y Perú al constituir uno de los pilares básicos de la alimentación de ambos países. El valor de estos productos para la economía del país es el siguiente:

Tabla $N^{\circ} 4$ - Evolución del precio de las exportaciones de arroz, frijoles y maíz en México y Perú, entre 2005 y 2016.

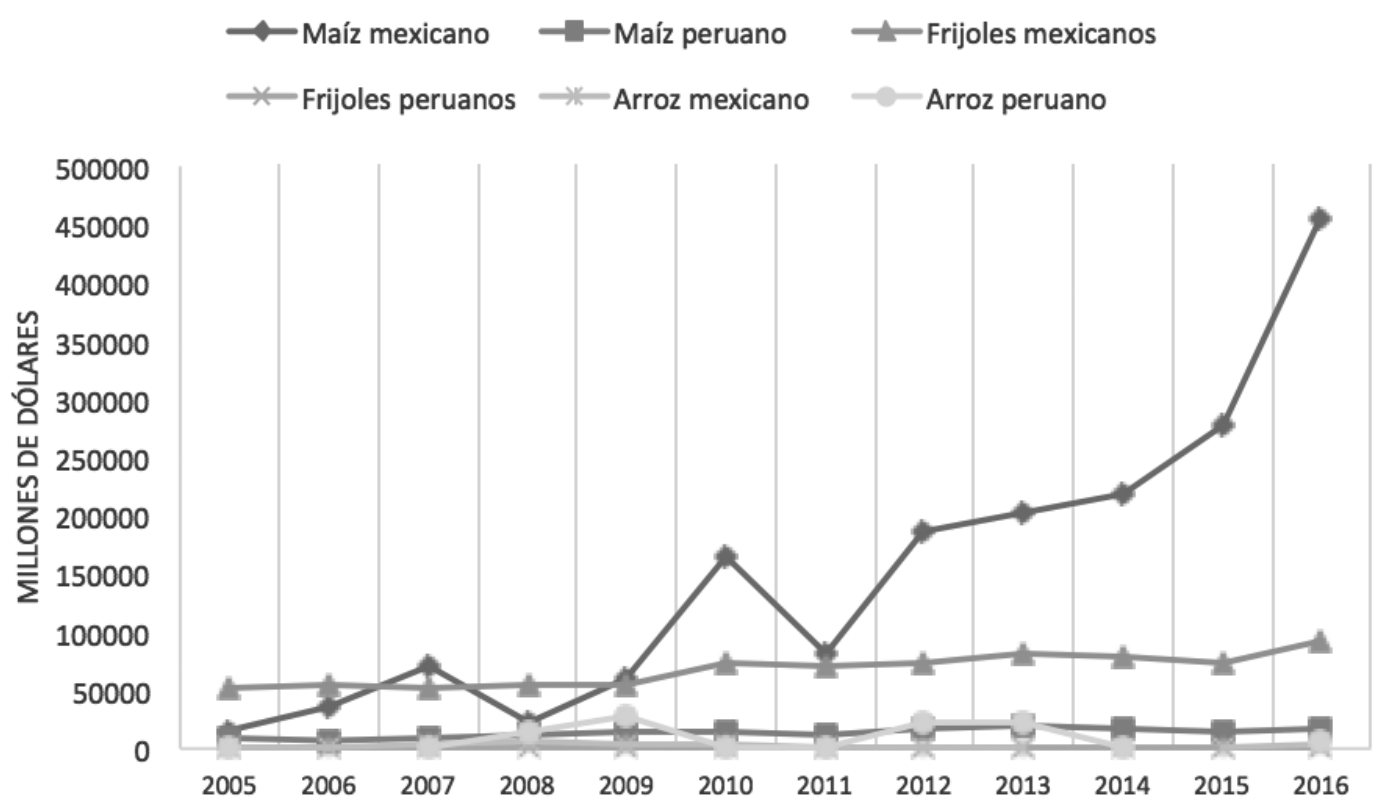

Fuente: Información de The Observatory of Economic Complexity - Evolución del precio de las exportaciones de arroz, frijoles, y maíz en México y Perú, 2005 y 2016.

Elaboración: Propia

Atendiendo al valor de las exportaciones de estos productos agrícolas, vemos que son muy inferiores si se comparan con los beneficios obtenidos por la explotación de plata. Como se observa en las tablas $\mathrm{N}^{\circ} 3$ y N 4 , el valor de la agricultura se expresa en millones de dólares, mientras que en el de la minería se indica en miles de millones de dólares, manifestando la disparidad existente entre dos productos que requieren de agua para su producción, pero cuya utilidad no puede ser comparable, ya que la agricultura satisface las necesidades básicas y biológicas de los sujetos.
A pesar de ello, en relación con el consumo de agua, debemos indicar que el $76 \%$ del total de agua concesionada en México va destinado a la agricultura, actividad cuyo mercado está controlado un $60 \%$ exclusivamente por diez empresas, siendo grandes productores los acaparadores de la mayor parte de los subsidios dados por el Estado (Fondo para la Comunicación y la Educación Ambiental, 2017).

Una situación similar es la vivida por Perú, donde a pesar de que la minería y los 
hidrocarburos representan el $12 \%$ del PIB, y la agricultura el $5 \%$, esta emplea el $76 \%$ del agua utilizada por el país, mientras que la usada por la industria y la minería es el 5\% (Autoridad Nacional del Agua, 2015, pág. 16).

Observamos que la situación del agua en México es paradójica, en la medida que los principales núcleos económicos y de población del país, son aquellos con menor disponibilidad de agua, como puede apreciarse en los siguientes gráficos:

\section{Tabla $N^{\circ} 5$ - Relación de cantidad existente de agua renovable y población por} Estado en el año 2015.

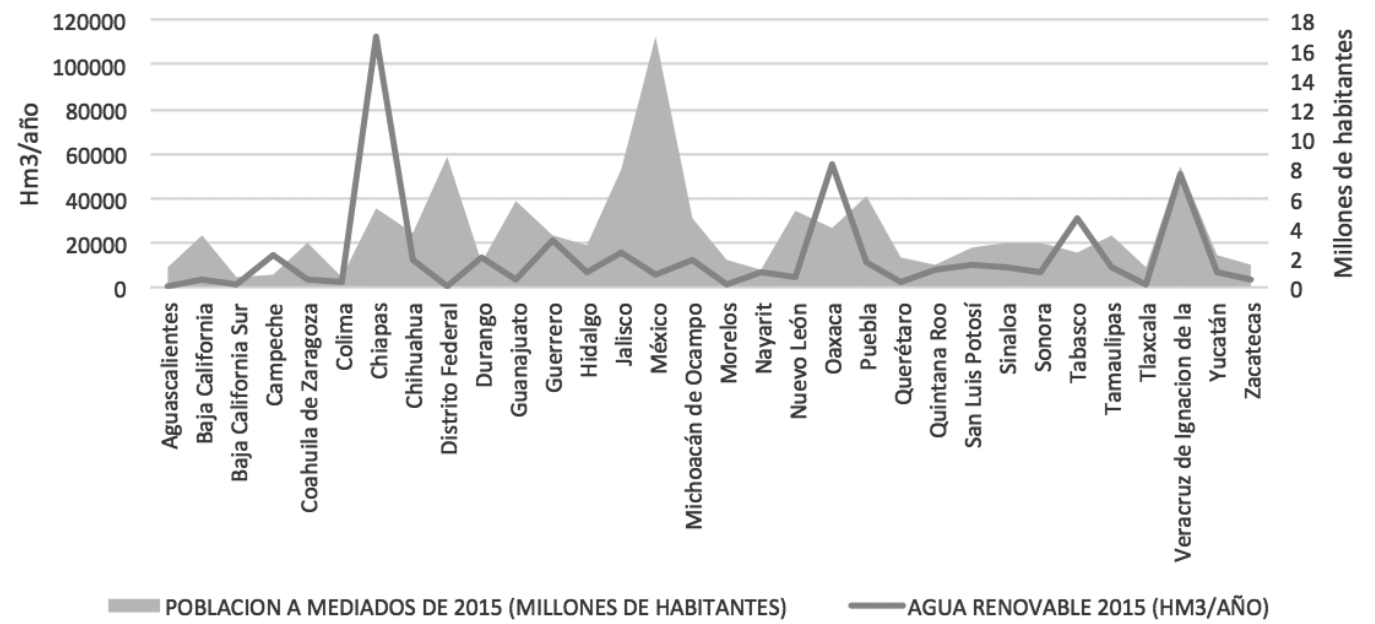

Fuente: Información contenida en el documento de CONAGUA "Estadísticas del Agua en México - Edición 2016". Elaboración: Propia

Tabla $N^{\circ} 6$ - Relación por Estados entre el agua renovable per cápita en 2015 y la aportación al PIB nacional en 2014.

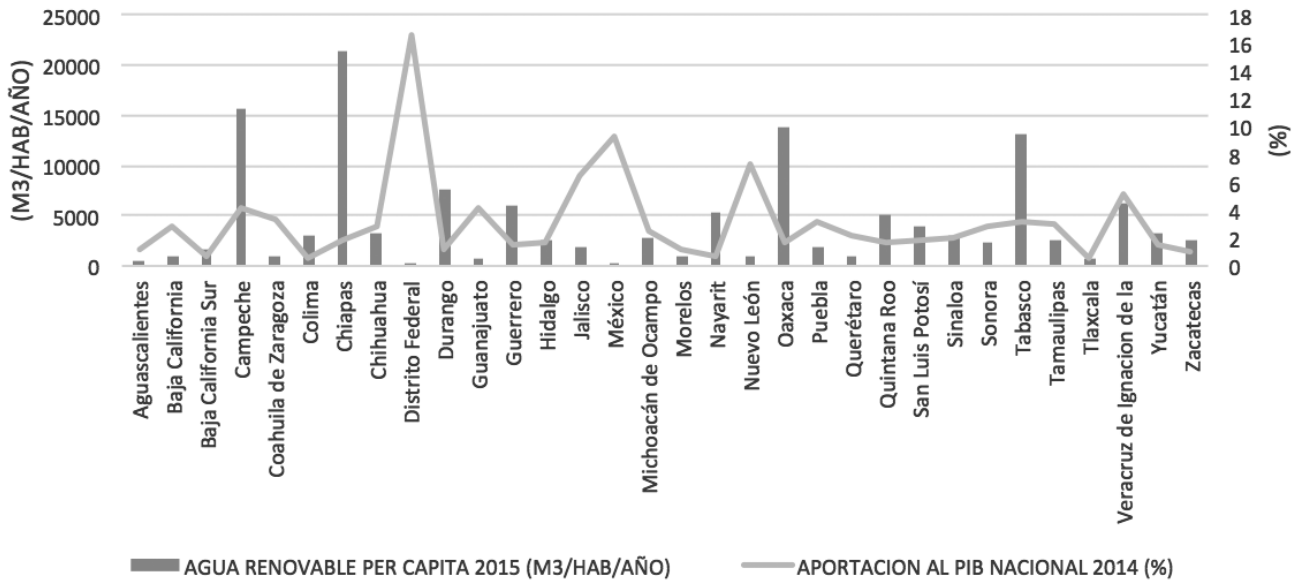

Fuente: Elaboración propia de acuerdo con la información contenida en el documento de CONAGUA "Estadisticas del Agua en México - Edición 2016".

Elaborado: Propia. 
En el caso de Perú, se obtuvo limitada información relativa a la disponibilidad de agua por departamentos. Los únicos datos encontrados (y de utilidad para este estudio) fueron los referentes a la producción media de agua potable en el país entre los años 2015 y 2016, que fue de $105732500 \mathrm{~m} 3$ (Instituto Nacional de Estadística e Informática, 2017, pág. 28), y la disponibilidad hídrica en el ámbito nacional, según vertiente Atlántica (compuesta por 44 cuencas hidrográficas, representa el $74 \%$ del territorio nacional) Pacífico (con 53 cuencas hidrográficas, representa el $22 \%$ del territorio nacional) y Titicaca (apenas el
4\% del territorio) (Ministerio de Agricultura y Riego de Perú, 2015) en 2014: Atlántico (2 $438218 \mathrm{hm} 3$ ), Pacífico (37 $260 \mathrm{hm} 3)$ y Titicaca (6 $873 \mathrm{hm} 3$ ) (Instituto Nacional de Estadística e Informática, 2015). Por ello, no se ha podido indicar cuál es exactamente la disponibilidad hídrica en el departamento de Junín. Una descripción aproximada, por medio del cruzamiento de datos entre la información anterior y la contenida en el documento "Estado de la Población Peruana 2.015" (Instituto Nacional de Estadística e Informática, 2015) da como resultado el siguiente gráfico:

\section{Tabla $N^{\circ} 7$ - Relación de cantidad existente de agua renovable y población por vertiente en Perú.}

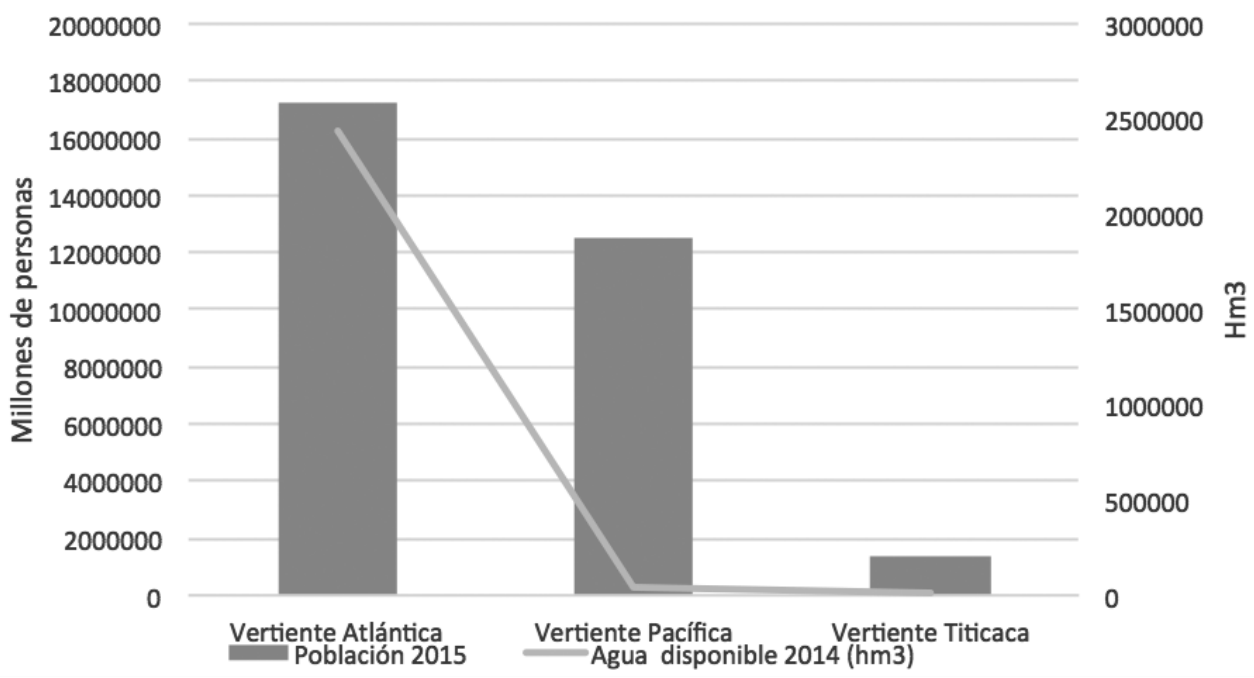

Fuente: Información contenida en el documento de "Estado Población Peruana 2.015" y "Anuario de Estadísticas Ambientales $2.015 "$.

Elaboración: Propia

En México, la dependencia encargada de proteger las aguas nacionales y los bienes públicos inherentes a las mismas corresponde a la Comisión Nacional del Agua (CONAGUA), que tiene por finalidad el que pueda contarse con una administración sostenible y garantizar la seguridad hídrica (Comisión Nacional del Agua, 2018). CONAGUA, regulada en el artículo 9 de la Ley de Aguas Nacionales (LAN), es un órgano administrativo (desconcentrado de la Secretaría) que se organiza en el ámbito nacional, y a nivel regional hidrológicoadministrativo, mediante sus Organismos de Cuenca.
Artículo 9. (...) Tiene por objeto ejercer las atribuciones que le corresponden a la autoridad en materia hídrica y constituirse como el Órgano Superior con carácter técnico, normativo y consultivo de la Federación, en materia de gestión integrada de los recursos hídricos, incluyendo la administración, regulación, control y protección del dominio público hídrico. (Ley de Aguas Nacionales)

En Perú, la Autoridad Nacional del Agua (ANA), tal y como establece el artículo 14 de la Ley de recursos hídricos nº 29338 "es el ente rector y la máxima autoridad técniconormativa del Sistema Nacional de Gestión 
el conflicto por el uso del agua en México y su potencial aplicación en el Perú

Alternative justice mechanisms as a daily justice policy in the face of the conflict over the use of water in Mexico and its potential application in Peru

de los Recursos Hídricos". Organismo del Ministerio de Agricultura y Riego, creado el 13 de marzo de 2008 mediante el Decreto Legislativo $n^{\circ} 997$, es quien tiene la misión de administrar, aprovechar, conservar, y proteger los recursos hídricos de las diferentes cuencas del Perú, de manera sostenible, promoviendo al mismo tiempo la cultura del agua (Autoridad Nacional del Agua, 2017).

\section{EL CONFLICTO HÍDRICO-MINERO EN EL ÁMBITO LOCAL}

El agua, como recurso escaso, ha sido siempre motivo de conflicto entre personas, comunidades y naciones (Shamir, 2003). Wright (2015) recogiendo el pensamiento de Barreira, González Aranao y Trejos Rosero, señala la relevancia que tiene para latinoamerica el estudio de los conflictos sociales, porque pese a ser una región caracterizada por la ausencia de guerras, existe "un alto índice de conflictividad social, que en ocasiones se ha acompañado de violencia". De igual manera, la gestión o resolución de conflictos, es tan antigua como la humanidad misma (United Nations, 2013), y la gestión deficiente de los conflictos sociales causa procesos de radicalización en los que la violencia produce enfrentamientos con resultados adversos $\mathrm{y}$ en ocasiones fatales (Defensoría del Pueblo, 2015) . $^{3}$

Como reconocía el Centro Internacional de Investigación e Información para la Paz (2000, pág. 178) la dificultad a la hora de estudiar el concepto de violencia se da por: su complejidad y dependencia del contexto en que esta se desarrolla; la dificultad de discernimiento entre la percepción subjetiva de violencia y la violencia real; y finalmente, por la ausencia de consenso entre los encargados de reprimir la violencia, la ciudadanía, y los gobernantes, respecto de la primacía entre los distintos tipos de violencia como amenazas a la paz social.

De acuerdo con la iniciativa Justicia Cotidiana (2016, pág. 130) Johan Galtung, sociólogo noruego precursor de la Cultura de Paz, estableció una clasificación, reconociendo tres

3 Un caso especialmente ejemplificativo fue el conocido como "la guerra del agua en Bolivia", sobre el particular véase Claire Wright y Hugo Salazar, Acuerdos comerciales internacionales y conflictos sociales: El caso de la "guerra del agua" en Bolivia, en Solución de conflictos en las relaciones comerciales internacionales, (Abraham A. Hernández y Arnulfo Sánchez Eds, Rechtikal, México, 2015. Pp. 377-396). tipos de violencia: directa, que es la modalidad visible, al darse entre las personas "cara a cara"; estructural, entendiéndose como aquella que parte de las instituciones mediante el reparto y jerarquización del poder, concretándose en la negación a las personas de necesidades básicas como son el agua, los alimentos, el desempleo, la pobreza o la seguridad; y cultural, estando constituida por aquellas creencias, símbolos $\mathrm{y}$ valores arraigados en una sociedad, que legitiman las relaciones de desigualdad y explotación, mostrados en los dos tipos anteriores.

Atendiendo a la clasificación anterior, desarrollada por Galtung en 1974, el Centro Internacional de Investigación e Información para la Paz (2000, pág. 179) adaptando a su vez la clasificación desarrollada por Moser y Shrader, diferenciaba, atendiendo a su alto grado de visibilidad, entre violencia económica, política y social, pudiendo ser descritas estas categorías colectivamente como todos aquellos actos de violencia motivados por el deseo, consciente o inconsciente, de obtener o mantener poder económico, político y/o social.

Junto con la violencia, debemos tener en cuenta el cambio climático, el cual, de acuerdo con Lysaght (2016) provoca una serie de fenómenos que tienen efectos visibles en el agua, como son las inundaciones, las sequías y las tormentas ${ }^{4}$. Atendiendo a esta realidad, Huntjens y Nachbar (2015) consideran el cambio climático como un multiplicador de amenazas en "países frágiles, donde las instituciones son débiles y la gobernanza es deficiente"5 (pág. 3). Además, como sostiente Kimmelman (2017) el cambio climático puede provocar "lluvias más fuertes e intensas, lo cual significa más inundaciones, pero también sequías más prolongadas y fuertes” (párr. 29).

En el mismo sentido se manifestaba en el año 2009 un informe del "Royal United Services Institute" (RUSI) titulado "impactos relacionados con el clima en la Seguridad Nacional de México y Centroamérica" al expresar como el cambio climático tendrá

4 Véase también Luis Miguel Galindo, et. al. Los efectos biológicos del cambio climático, 13 Ecosistemas: Revista Científica y Técnica de Ecología y Medio ambiente, 2004, No 1, pp.103-110.

5 Texto original: "fragile states where institutions are weak and governance is poor" 
consecuencias sociales y políticas dramáticas en Mesoamérica y las zonas vecinas, así como un cambio en la distribución de los recursos, haciendo que los desafíos sean más difíciles de afrontar (Fetzek, 2009). De aceptar esta idea en la cual el cambio climático puede incrementar factores de estrés socioeconómicos existentes en sociedades con exposición a los mismos, como son la pobreza (Navas Acevedo, García, \& Rodríguez Hernández, 2016) o la incapacidad institucional para adaptarse o mitigar los efectos del cambio climático, parece lógico que esas estrategias de adaptación o mitigación de los efectos serán claves para la consolidación de la paz (Huntjens \& Nachbar, 2015).

El cambio climático es un elemento multiplicador de las amenazas, que trasciende al ámbito estatal. Se trata de un fenómeno que no está constreñido a la limitación fronteriza, $\mathrm{y}$ ante la cual, los mecanismos institucionales estatales son sobrepasados por la magnitud de sus efectos. No se trata de un problema de ámbito local o regional, sino de carácter planetario, potencial generador de conflictos, cuyo tratamiento requiere de un doble enfoque: desde un plano superior, de acuerdo a nivel internacional entre los principales Estados que inciden negativamente en el ecosistema, al ser los principales contaminadores; y desde la base, a través de la concienciación y educación ciudadana, en un ejercicio estatal a todos los niveles administrativos.

Las posibilidades reales de alcanzar un acuerdo internacional podrían ser consideradas en la actualidad cercanas a la utopía, dada la disparidad concurrente de intereses por las implicaciones que tiene la energía para los Estados. Tanto por razones de elección de modelo económico de desarrollo, como de seguridad nacional, resulta factible que el medio adecuado para lograr una transformación del conflicto sea el de mitigar la conflictividad en la sociedad.

Unido a la idea del cambio climático como multiplicador de amenazas, América Latina ha experimentado situaciones conflictivas graves en torno al agua, como las sucedidas en la Cochabamba (Bolivia) en el año 1999, que provocó un muerto y varios heridos (Ramírez \& Yepes, 2011, pág. 161), o en Cajamarca (Colombia) donde se efectuó una consulta ciudadana el 27 de marzo de 2017, que dio como resultado el no del $97,9 \%$ de la población al proyecto de la Mina La Colosa por las implicaciones negativas que podía provocar en el agua de la región (López Ga., 2017).

Igualmente debemos tener presente, en referencia a México, la mercantilización de terrenos comunales. Sobre el particular, Guzmán López (2016b) indica que respecto de los conflictos internos acaecidos entre los campesinos partidarios y detractores de esa práctica, sobre terrenos que en origen eran destinados a actividades agrícolas y ganaderas, se produce una modificación social en las regiones, en la medida en que poblaciones tradicionalmente agrícolas se insertan en la producción minera sin que exista unanimidad al respecto, lo que afecta al sentido de pertenencia y la cohesión de estas comunidades.

En Perú, los departamentos de Áncash (principal productor nacional de zinc, segundo de cobre y tercero de plata) Lima (segundo productor nacional de plata) y Cajamarca (segundo productor nacional de oro) (Sociedad Nacional de minería, petróleo y energía, 2017) son los departamentos que de acuerdo con el Informe "Conflictos Sociales y recursos hídricos" de la Defensoría del Pueblo (2015), tuvieron más conflictos sociales en relación al agua, del total de los 153 conflictos registrados ocurridos entre los años 2011-2014: Áncash, con 20 casos, Lima, con 13 y Cajamarca con 12.

Áncash, Lima y Cajamarca son los departamentos (junto a Puno) donde se ubican la mayoría de los 8500 pasivos ambientales mineros existentes en el país, entendidas como antiguas zonas mineras en que se ocasionaron daños ambientales que quedaron sin reparar (Defensoría del Pueblo, 2015). A su vez, el $75 \%$ de los 153 conflictos ocurridos en Perú, se desarrollaron "en zonas rurales, generalmente con altos niveles de pobreza, una escasa presencia del Estado y un bajo índice de desarrollo humano" (Defensoría del Pueblo, 2015, pág. 143).

Podemos citar algunos ejemplos de la relación conflictiva existente entre las empresas mineras y las comunidades en que se ubican, principalmente en torno a los accidentes ecológicos, y el aprovechamiento y distribución de los recursos hídricos. Esta agua suele ser la denominada como agua de mina, al ser extraída de una, que previo tratamiento puede utilizarse para labores de riego y ciertas 
Alternative justice mechanisms as a daily justice policy in the face of the conflict over the use of water in Mexico and its potential application in Peru

actividades domésticas y servicios urbanos (Gobierno del Estado de Zacatecas, 2015). Indicamos como la minería a cielo abierto es el procedimiento más habitual en la extracción de minerales estratégicos, a pesar de ser dañino al medio ambiente puesto que, durante el proceso de separación, la mezcla de roca pulverizada y líquido producido por medio de elementos tóxicos y radiactivos, pueden filtrarse si no son adecuadamente contenidos (Massachusetts Institute of Technology, 2013).

Así, nos encontramos con tres supuestos ejemplificadores de situaciones conflictivas que ocurren en torno a la actividad minera en el Estado de Zacatecas. En primer lugar, el representado por las localidades limítrofes con la Minera Saucito, perteneciente al grupo Fresnillo PLC, que extrae una media de 15 litros por segundo de agua, que si bien no es apta para consumo humano, si lo es para el riego de cultivos y de suministro para los abrevaderos del ganado (Crespo, 2016). Dicha empresa fue acusada de contaminar en el municipio de Fresnillo a la comunidad Saucito del Poleo, por el derrame de 450 toneladas de residuos minerales al producirse la ruptura de un conducto el 6 de diciembre de 2015, que afectó a una extensión de 8000 metros cuadrados propiedad de la empresa, y a 1600 metros cuadrados de una parcela contigua (Zacarías, 2015). El ejido Saucito cuenta con una población en torno a 260 habitantes dedicados a trabajar en el sector minero (Ríos, 2016) tras haber abandonado la actividad agrícola de cultivo de frijol a la cual se dedicaba esta comunidad con anterioridad (Zacarías, 2015).

En segundo lugar, otro supuesto también acontecido en el Estado demuestra el conflicto existente respecto al uso y aprovechamiento del agua. Es el caso del Bajío de La Tesorera, donde su población dedicada a la agricultura de subsistencia, solo cuenta con un pozo (excavado a 300 metros de profundidad) que abastece el riego de 86 de un total de 300 ejidatarios, siendo operado por la empresa minera Arian Silver, encargada de la distribución del agua al encontrarse el afluente en sus terrenos de la mina San José (Valadez Rodríguez, 2017a).

En opinión de los habitantes de las comunidades de Bajío de La Tesorera y de Santiaguillo, localidades pertenecientes al municipio de Pánfilo Natera, la empresa minera había incumplido un acuerdo de dotación con las comunidades (140 mil metros cúbicos de agua para el riego de cultivos) por lo que bloquearon el acceso a la mina (Valadez Rodríguez, 2017b). Dos días después, tras una reunión mantenida entre representantes del ejido, directivos de la empresa, miembros de la Procuraduría Agraria, CONAGUA, Secretaria de Agricultura, Ganadería, Pesca y Alimentación (SAGARPA), y miembros de los gobiernos municipales y estatales del Partido Revolucionario Institucional (PRI), se levantó el bloqueo, porque en declaraciones a los medios de comunicación, el Comisariado Ejidal declaró que había sido obligado a ello (Valadez Rodríguez, 2017a).

Por último, un tercer supuesto, que conjuga las dos situaciones anteriormente expuestas, lo encontramos en la mina Peñasquito, principal productora de oro en México, y gestionada por la empresa Goldcorp, cuyos accesos fueron bloqueados por unos 200 transportistas y decenas de ejidatarios junto a sus familias como protesta por el incumplimiento de convenios firmados por la empresa con las comunidades (Valadez Rodríguez, 2016a) afectadas por la extracción y contaminación del agua hasta agotar los acuíferos, y por provocar que las tierras no sean aptas para cultivo (NTR Zacatecas, 2016).

Tras 12 días en que se sostuvo el bloqueo, las negociaciones mantenidas entre directivos de la compañía y las comunidades, dieron fin al mismo, tras el compromiso por la empresa de compensar a los habitantes de los ejidos afectados por las pérdidas de sus cosechas en los últimos años, y de hacerse cargo del mantenimiento del único pozo de agua que quedaba en la zona, así como la contratación de un número determinado de habitantes de la región (Valadez, 2016b).

Si tomamos los ejemplos analizados respecto de la conflictividad existente en torno a las explotaciones mineras, vemos como nos encontramos ante supuestos en los que se conjugan las vertientes económica, política y social; donde en caso de no ser atendidas las reivindicaciones de la ciudadanía (lo que supone un claro ejemplo de violencia estructural) podrían perfectamente surgir otros tipos de violencia, ante la percepción subjetiva de abandono por las comunidades afectadas, abonadas por la desigualdad y la pobreza. Estas 
situaciones podrían desembocar en violencia directa, a través de acciones armadas de lucha, motivadas por el descontento popular. Así, todas estas manifestaciones suponen elementos desestabilizadores y amenazas a la paz social de las regiones que experimentan estas realidades ${ }^{6}$, motivos que han de ser tenidos en cuenta a la hora de planificar políticas públicas más inclusivas y tendentes a minimizar estos riesgos.

\section{LOS ORGANISMOS DE CUENCA Y LA INTERVENCIÓN DE LOS USUARIOS DE AGUA A TRAVÉS DE UNA POLÍTICA NACIONAL DE APLICACIÓN DE MECANISMOS ALTERNATIVOS DE SOLUCIÓN DE CONTROVERSIAS}

En la planificación de la asignación del agua de las cuencas, la UNESCO prevé una serie de principios para determinar la asignación de recursos hídricos, los cuales reconoce que han sido ya adoptados por algunos ordenamientos: equidad; protección medioambiental; prioridades de desarrollo; equilibrio entre la oferta y la demanda, y promoción del uso eficiente del agua (Organización de las Naciones Unidas para la Educación, la Ciencia y la Cultura, 2013).

En México, la LAN, con la finalidad de mejorar el aprovechamiento del agua y la preservación y control de su calidad, establece en sus artículos 14 y 14 bis, que CONAGUA promueva y apoye la organización de los usuarios del agua en el ámbito nacional, estatal, regional o de cuenca, y su participación en la planeación, toma de decisiones, ejecución, evaluación y vigilancia de la política nacional, por medio de la labor conjunta de CONAGUA y los Gobiernos de los estados, del Distrito Federal y de los municipios, los organismos de cuenca, los consejos de cuenca y el Consejo consultivo del Agua.

\footnotetext{
6 Un ejemplo de este escenario lo encontramos en el conocido como "Moqueguazo", el cual, de acuerdo con la explicación dada por Meléndez y León (2009, págs. 605-606) fue un paro ocurrido en la región peruana de Moquegua, en junio de 2008, como protesta frente al descontento provocado por la menor cuota minera que recibia esta provincia por la por la menor cuota minera que recibia esta provincia por la el secuestro de 60 policías, lo que llevó al gobierno a aceptar las reivindicaciones, y a legislar en los meses posteriores, aumentando con ello la cuota minera percibida por esta provincia, con lo que puede afirmarse que estas protestas tuvieron un impacto a escala nacional.
}

CONAGUA realiza sus funciones a través de los Organismos de Cuenca, cuyo ámbito de competencia son las regiones hidrológicoadministrativas. Existen trece Organismos de Cuenca coincidentes con las trece regiones hidrológico-administrativas en que se encuentra dividido el país, las cuales están formadas por agrupaciones de cuencas, consideradas como las unidades básicas para la gestión de recursos hídricos. Los límites de las regiones respetan la división política municipal, para facilitar la administración e integración de datos socioeconómicos (Comisión Nacional del Agua, 2017).

Como hemos indicado, CONAGUA se sirve de los Organismos de Cuenca (definidos en la LAN en el artículo 3.XXXIX). De igual manera, conforme a los artículos 14 y 14 BIS de la LAN, CONAGUA, con apoyo de los Consejos de Cuenca, y a través de los Organismos de Cuenca (que son unidades técnicas, administrativas y jurídicas especializadas) desempeña numerosas funciones respecto de los diversos actores que intervienen en el uso y la gestión del agua.

Es de esta manera como se ordena el sistema hídrico mexicano, compuesto por las instituciones tomadoras de decisiones y operativas, responsables de la implementación de la política hidrológica en las diferentes zonas del país, la cual en su ejecución (tomando en cuenta los principios rectores establecidos por la UNESCO) es lógico que genere conflictos en materia de disponibilidad de aguas.

El estado de Zacatecas se encuentra comprendido entre las siguientes Regiones Hidrológicas Administrativas (Gobierno del Estado de Zacatecas, 2015): III - Pacífico Norte, a la que pertenece la célula de planeación de Valle de Guadiana; VII - Cuencas Centrales del Norte, a las que pertenecen las células de planeación de Cuenca Alta Aguanaval y Cuenca El Salado; VIII - Lerma-SantiagoPacífico, en la cual se integran las células de planeación de Alto Santiago y Bajo Santiago. Como puede verse en el siguiente gráfico, el promedio del agua renovable per cápita existente en el Estado de Zacatecas es inferior a la media nacional: 
Alternative justice mechanisms as a daily justice policy in the face of the conflict over the use of water in Mexico and its potential application in Peru

Tabla $\mathrm{N}^{\circ} 8$ - Comparativa del agua renovable per cápita de las tres regiones hidrológicasadministrativas que convergen en el Estado de Zacatecas, su promedio, y la media nacional.

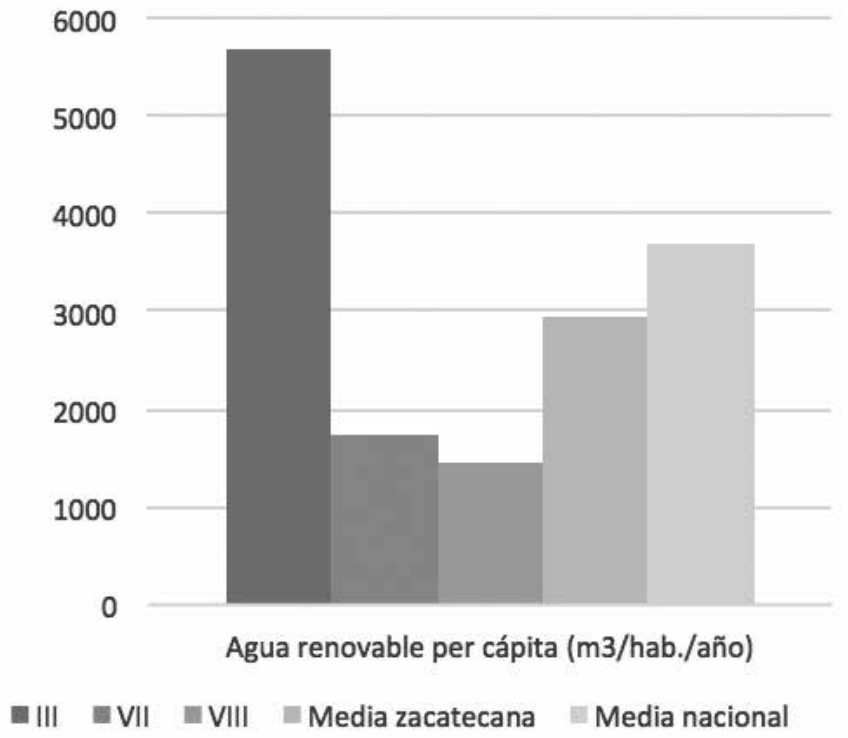

Fuente: Información contenida en el documento de CONAGUA "Atlas del Agua en México- Edición 2016". Elaboración: Propia

Si bien el volumen de agua concesionada en México se destina mayoritariamente a la agricultura, que representa un $76,3 \%$ del total (el abastecimiento público representa el $14,6 \%$, la industria autoabastecida el $4,3 \%$, y la cantidad restante es destinada a la generación de energía eléctrica, excluyendo la hidroelectricidad) (Comisión Nacional del Agua, 2016) en el caso de Zacatecas, Guzmán López (2016a) muestra una comparativa de como "los 55.78 millones de metros cúbicos de agua concesionados a los megaproyectos de capital global de minería, permiten abastecer a 1 millón 528 mil 247 personas" (pág. 176).

Ello estaría dentro de la línea seguida por las compañías mineras en todo el país, puesto que como pone de manifiesto la iniciativa civil CartoCrítica (2016), en el periodo de 2014 la industria minera extrajo 437 millones de metros cúbicos de agua en el país, siendo esta cifra suficiente para cubrir las necesidades de 3,61 millones de personas ${ }^{7}$ en el mismo periodo. El

7 La suma de las poblaciones de Baja California Sur, Campeche, Colima y Nayarit. estado de Zacatecas, forma parte del Consejo de Cuenca de Nazas Aguanaval, Altiplano y Río Santiago, cada una de las cuales, dotadas de unas reglas de integración, organización y funcionamiento de sus Consejos de Cuenca (Comisión Nacional del Agua, 2011).

Las "Reglas Generales de Integración, Organización y Funcionamiento del Consejo de Cuenca de Río Santiago", en su artículo 74 establece que los Comités de Usuarios y los Comités de la Sociedad Organizada son:

[...] la célula básica de participación social en el Consejo, donde se organizan los Usuarios de las Aguas Nacionales, la Sociedad Organizada y el Sector Académico, para participar en el Consejo de Cuenca, sus órganos auxiliares y sus órganos funcionales", estando cada Comité agrupado por los usuarios de acuerdo con el tipo de uso a que destinan en agua a los usuarios, o los integrantes de Organizaciones de la Sociedad, o los representantes del Sector Académico existentes en el ámbito territorial del Consejo o del órgano auxiliar correspondiente (Comisión Nacional del Agua, 2011). 
A su vez en el artículo 78 se establece cuáles son las funciones y obligaciones de los comités de usuarios por uso, de la sociedad organizada y del sector académico:

a) Ser el enlace entre los usuarios, la Sociedad Organizada y del Sector Académico que representan y sus respectivas asambleas. b) Apoyar la solución de la problemática que en materia de aguas se presente en el ámbito territorial correspondiente. c) Promover, difundir y coordinar la participación de todos los Usuarios de Aguas Nacionales, de la Sociedad Organizada y del Sector Académico en su ámbito territorial. d) Contribuir al cumplimiento de los acuerdos del Consejo y sus órganos auxiliares. (Comisión Nacional del Agua, 2011).

En el mismo sentido se expresan las "Reglas Generales de Integración, Organización y Funcionamiento del Consejo de Cuenca de Nazas Aguanaval" en parte porque comparten numeración y contenido del articulado, salvo por el detalle de que en el artículo 78 se omite "Sector Académico" de su enunciado (Comisión Nacional del Agua, 2014).

Adicionalmente cuenta con el Capítulo XIV, relativo a la participación ciudadana, que da la posibilidad a que pueda asistir la ciudadanía a las reuniones de la Comisión de Operación y Vigilancia (COVI, que desempeña su labor como Órgano Funcional del Consejo de Cuenca) o a las sesiones del Consejo, pero en todo caso será la COVI quien considere tal asistencia (Comisión Nacional del Agua, 2014). Esta posibilidad es un mecanismo pensado para transparentar el proceso de toma de decisiones sobre el destino y utilización del agua en la cuenca.

Las "Reglas Generales de Integración, Organización y Funcionamiento del Consejo de Cuenca del Altiplano" (que comprende los Estados de Nuevo León, San Luis Potosí, Tamaulipas y Zacatecas) igualmente contempla la figura de los Comités de Usuarios y los Comités de la Sociedad Organizada en su artículo 78, agrupando a los usuarios de un determinado uso del agua, o a integrantes de organizaciones de la sociedad, o a los representantes del sector académico para participar (Comisión Nacional del Agua, 2014).

En su artículo 82, que regula cuales son las funciones y obligaciones de los Comités de Usuarios por Uso, de la Sociedad Organizada y del Sector Académico (las mismas que las expresadas en el Consejo de Cuenca de Nazas Aguanaval y Rio Santiago) se incluye la posibilidad de que los miembros del Comité puedan "invitar a sus sesiones a representantes de las diversas agrupaciones de la sociedad interesada cuya participación se considere conveniente para el mejor funcionamiento del mismo".

El elemento diferenciador de las reglas de la Cuenca del Altiplano respecto de las dos Cuencas anteriores, se encuentra en su Capítulo $\mathrm{XIV}$, que lleva por rúbrica "La solución de controversias", cuyo artículo 83 establece:

Para coadyuvar con la Comisión en la solución de controversias que se susciten en materia de aguas en el ámbito de competencia del Consejo, se implementará en los Órganos Auxiliares el uso de métodos alternativos a los procesos judicial y de la Comisión para la solución de las controversias. Los métodos alternativos utilizados serán la transacción, la mediación y la conciliación (Comisión Nacional del Agua, 2014).

Ahora bien, resolver los conflictos sociales debe ser una prioridad estatal, lo cual se acentúa cuando se trata de disputas sobre bienes o cuestiones sensibles, siendo el acceso al agua un tema vital, de máxima importancia y sensibilidad para la sociedad en general. Es por ello que se ha creado el sistema de solución de controversias antes descrito, en base a la necesidad de solventar de manera negociada y rápida, tomando en cuenta la opinión de los distintos actores sociales, que son quienes finalmente padecen los efectos de los problemas suscitados en torno a los recursos hídricos.

La visión de incluir un sistema de aplicación de MASC parece engarzarse perfectamente en las recomendaciones hechas por distintas instituciones internacionales para atender este problema. En lo específico, la Comisión Interamericana de Derechos Humanos(2007) ha insistido en la necesidad urgente de romper los obstáculos que imposibilitan o limitan el acceso a la justicia, o el acceso igualitario.

En ese contexto, los MASC constituyen, frente al sistema tradicional de justicia estatal, una alternativa basada en técnicas flexibles y de aplicación voluntaria, destinada a la solución asistida de conflictos. De acuerdo con Gorjón Gómez (2015) los MASC tienen una vocación 
Alternative justice mechanisms as a daily justice policy in the face of the conflict over the use of water in Mexico and its potential application in Peru

originada en la tutela a través de la ley y el impulso de políticas públicas sustentadas en las leyes modelo y en las convenciones internacionales, donde en algunos países, como es el caso de México, se han recogido en sus propios textos constitucionales.

En 2008 México reformó la Constitución Política de los Estados Unidos Mexicanos, al adicionar a su artículo 17, el párrafo cuarto, el cual establece que "Las leyes preverán mecanismos alternativos de solución de controversias. En la materia penal regularán su aplicación, asegurarán la reparación del daño y establecerán los casos en los que se requerirá supervisión judicial"». Dicha reforma, como reconocen Gorjón Gómez y Steele Garza (2016) asume principios internacionales derivados de leyes modelo como las producidas por la Comisión de las Naciones Unidas para el Derecho Mercantil Internacional (CNUDMI) o con normas propias de la Convención de Nueva York de 1958 y la Convención de Panamá de 1975, estando ambas ratificadas por México, encontrándose dichos principios y políticas públicas en los tratados de libre comercio que el país tiene suscritos.

Por su parte, Wright (2015) sostiene que "en el contexto de importantes desigualdades sociales y presiones políticas, la resolución pacífica y democrática de conflictos es un desafío importante para muchos gobernantes". Por ello, ante este escenario, los MASC se perfilan como la herramienta necesaria para atender y resolver estas problemáticas surgidas en torno al aprovechamiento y distribución del agua, que van a verse agravadas como consecuencia del cambio climático.

Atendiendo a esta realidad, y ante la necesidad de encontrar soluciones con que poder afrontar estas problemáticas, surgió la iniciativa Justicia Cotidiana, cuyo origen se remonta al 27 de noviembre de 2014, fecha en la que el expresidente de México, Enrique Peña Nieto, en un mensaje a la Nación denominado "Por un México en paz, con justicia y desarrollo" dijo "Pero la justicia no se agota, hay que decirlo, en el ámbito penal. Hay una justicia olvidada, la justicia cotidiana (...)"; sentando

8 En este sentido, México promulgó el 29 de diciembre de 2014, la Ley Nacional de Mecanismos Alternativos de Solución de Controversias en materia Penal (LNMASCP) por medio de la cual, se ha dado un paso más en el logro de la participación de la sociedad en la solución extrajudicial de sus problemas. con este mensaje las bases para el desarrollo de propuestas y recomendaciones para atender esta materia, encomendándole la labor al Centro de Investigación y Docencia Económicas (CIDE) (Centro de Investigación y Docencia Económicas, 2015).

Como expresa el CIDE, la justicia cotidiana, junto con el acceso a la justicia derivan del artículo 17 de la Constitución Política de los Estados Unidos Mexicanos, junto con los artículos 8 y 25 de la Convención Americana sobre Derechos Humanos, dando como definición de justicia cotidiana "las instituciones, procedimientos e instrumentos orientados a dar solución a los conflictos que genera la convivencia diaria en una sociedad democrática" (Centro de Investigación y Docencia Económicas, 2015)

Uno de los elementos detectados por el CIDE, dentro del marco preliminar de investigación "Justicia para las comunidades y los vecinos" fue el desconocimiento existente entre la población sobre a qué instancias recurrir en los casos de denuncia de una obra o extracción ilegal de minerales (Centro de Investigación y Docencia Económicas, 2015)9.

Posteriormente, en 2016 se publicó el informe "Diálogos por la Justicia Cotidiana" en el que se detectaron las siguientes problemáticas respecto de la situación experimentada por México: en primer lugar, si bien el artículo 17 constitucional establece que la impartición de justicia es gratuita, "la realidad es costosa en cuanto a los gastos directos en indirectos"; en segundo lugar, existe desconfianza por la población hacia autoridades, instituciones, procedimientos y operadores de procuración y administración de justicia, como consecuencia de la corrupción (Justicia Cotidiana, 2016, pág. 146).

\section{LA PROBLEMÁTICA GENERADA EN EL CONTEXTO DE LOS MASC}

La CIDE detectó la ausencia de personal cualificado para gestionar los conflictos comunitarios utilizando mecanismos

\footnotetext{
9 En un sentido más amplio, podriamos decir que entendemos por justicia cotidiana aquella que se desenvuelve para dar solución a las desavenencias, disputas, incidentes y reclamaciones, producidas en el seno normal de la rutinaria convivencia de una sociedad de régimen democrático, con el objeto de lograr la armonía y la paz social, quedando excluido de su ámbito la justicia penal.
} 
alternativos de solución de controversias, como la mediación, junto con una "escasa cultura y consecuente desacreditación de los valores mínimos de convivencia social" y la "poca utilización de los Centros de Justicia Alternativa" como consecuencia, de acuerdo con el CIDE, de que "han sido insuficientes los esfuerzos para promover el uso de la mediación, la conciliación e incluso el arbitraje en asuntos civiles, mercantiles, de arrendamiento, corporativos o del derecho de familia que son más susceptibles de ser abordados a través de estos procedimientos" (Justicia Cotidiana, 2016, pág. 147).

Igualmente, en el marco de investigación de esta iniciativa, se detectó "la ausencia de políticas públicas integrales en materia de justicia" sin que exista "una función formal de dirección o coordinación técnica de toda la política pública de justicia" a pesar de las atribuciones con que cuenta el Ejecutivo federal; y la existencia de un gran número de dependencias, entidades y organismos constitucionales autónomos, en todo caso la insuficiente existencia de "mecanismos formales de coordinación entre las dependencias y entidades del Gobierno Federal que tienen a su cargo funciones en materia de justicia así como de coordinación y colaboración técnica e institucional entre el Poder Ejecutivo y los poderes judiciales federal y locales"; debiendo agregar a lo anterior la elevada complejidad que tiene la legislación existente, lo cual afecta negativamente en el acceso de la ciudadanía a la justicia (Justicia Cotidiana, 2016, pág. 229).

Hemos visto en el presente estudio, que uno de los supuestos habituales en los conflictos mineros es el lugar en el que se desarrollan estas hostilidades: ámbitos rurales al que han de desplazarse los elementos intervinientes en las negociaciones (sin olvidar la desigualdad de fuerzas existentes entre las partes enfrentadas).

La iniciativa de Justicia Cotidiana identificó como la orografía de algunas regiones de México dificultaba el establecimiento de una infraestructura institucional que pudiera atender a las necesidades de los ciudadanos, encontrándose en ocasiones los centros de Justicia Alternativa enclavados en ubicaciones que no son accesibles para parte de la ciudadanía, por encontrarse viviendo en asentamientos lejanos a los núcleos de población.

Es por ello, que atendiendo a la realidad que vive México (el $14^{\circ}$ país más grande por extensión territorial del mundo) que la mesa recomendó "promover la creación de mecanismos de justicia itinerante en las regiones en las que por sus características geográficas y socioeconómicas requieran de este servicio" (Justicia Cotidiana, 2016, pág. 206) lo cual podría resultar beneficioso para paliar los efectos negativos que puede provocar la explotación minera en las poblaciones aledañas.

La topografía de México y su extensión geográfica, propician que la administración de justicia pueda ofrecer servicios acordes a la realidad de su población, caracterizada por la existencia de asentamientos situados en regiones de difícil acceso, que es donde suelen ubicarse las explotaciones agrícolas y mineras, alejadas de grandes núcleos urbanos, donde se encuentran los tribunales de justicia. Por esta razón, las políticas de justicia cotidiana son necesarias para países que cuentan con una realidad semejante, caracterizada por la existencia de poblaciones en lugares recónditos, donde se contraponen los intereses respecto del uso y aprovechamiento del agua entre la actividad extractiva de minerales y los trabajos agrícolas, como ocurre en Perú.

En este último país, el artículo 24 de la Ley de recursos hídricos 29.338, se encarga de regular los Consejos de Cuenca. Concretamente, en el territorio del departamento de Junín, de acuerdo con el Decreto Supremo $n^{\circ} 87$ 2204, se divide en las Cuencas de los ríos: Ene, Mantaro, Perené, Tambo, y Urubamba (Proyecto ZEE Junín, 2015), disponiendo de las siguientes cantidades de agua en el año 2011 (Zonificación Ecológica y Económica de la Región de Junín (ZEE), 2016): 
el conflicto por el uso del agua en México y su potencial aplicación en el Perú

Alternative justice mechanisms as a daily justice policy in the face of the conflict over the use of water in Mexico and its potential application in Peru

\section{Tabla N 9 - Comparativa del agua disponible en las cuencas de los ríos Ene, Mantaro, Perené, y Tambo, en hm3, en el año 2011.}

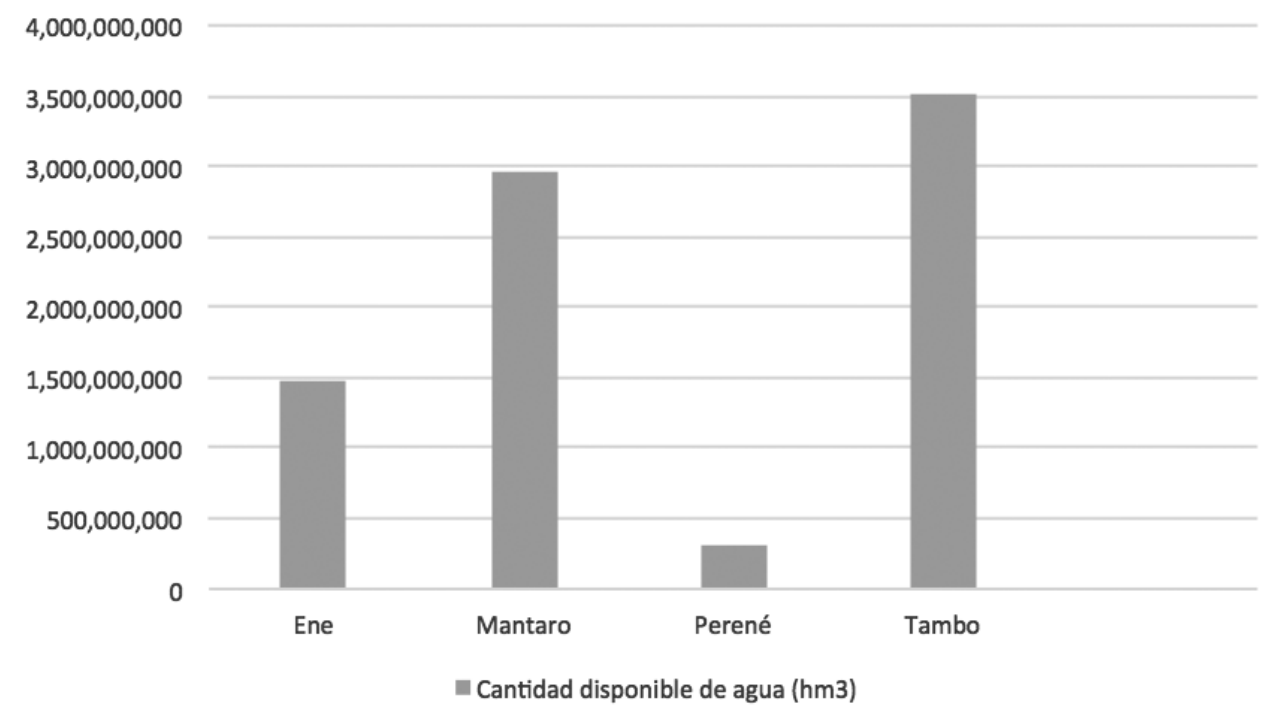

Fuente: Información contenida en el documento del Sistema Regional de Información Ambiental (SIAR) de Junín "Memoria descriptiva del estudio hidrológico y de cuencas del departamento de Junín a escala 1:100000".

Elaboración: Propia

Perú desarrolló inicialmente los MASC por medio de la Ley de Conciliación Extrajudicial, Ley 26.872, publicada en 1997 (y su Reglamento, aprobado por Decreto Supremo $\mathrm{N}^{\circ}$ 001-98-JUS, de 1998) que fue modificada en junio de 2008, por medio del Decreto legislativo 1.070 (contando con un nuevo Reglamento, aprobado por Decreto Supremo No 014-2008JUS, de $\left.2008^{10}\right)$; sin que en ningún caso se haya producido ninguna reforma constitucional a fin de dotar de mayor protección a los MASC. Si bien la Constitución Política del Perú no dedica ningún artículo a los MASC, en su Título III, del régimen económico, el art.63 contempla, en relación con las controversias contractuales entre el Estado y las personas de derecho público con extranjeros domiciliados en el país, que puedan someter dichas controversias a "arbitraje nacional o internacional, en la forma en que lo disponga la ley".

Respecto de la resolución de controversias que surjan en torno al agua en Perú, la Política de Estado sobre los Recursos Hídricos, aprobada

10 Puede consultarse en: http://cdn01.pucp.education/carc/ wp-content/uploads/2017/07/05211342/reglamento-dela-ley-de-conciliacion-d-1-n-1070.pdf el 14 de agosto de 2012, decía en su apartado i) lo siguiente:

Priorizará la prevención y gestión de controversias sobre el agua y temas afines, a través de las instancias desconcentradas y con la participación activa de los usuarios. Un órgano autónomo especializado de la Autoridad Nacional del Agua resolverá las controversias, en última instancia administrativa. De ser el caso, aplicará las sanciones requeridas en el ejercicio de su soberanía sobre el recurso natural agua aplicando la normativa para un debido procedimiento (Secretaría Ejecutiva del Acuerdo Nacional, 2012).

El órgano autónomo al que se hace mención es el Tribunal Nacional de Resolución de Controversias Hídricas. Perteneciente a la ANA, este Tribunal, que tiene competencia nacional, opera desde el año 2014, encargándose de la resolución en última instancia de las reclamaciones y recursos contra los actos administrativos emitidos por los Órganos Desconcentrados, y los órganos de línea de la ANA; y cuyas decisiones pueden ser impugnadas exclusivamente por vía judicial (Autoridad Nacional del Agua, 2017). 


\section{CONCLUSIONES Y PROPUESTAS}

Por lo anteriormente expuesto podemos afirmar que nos encontramos ante una situación en que se contraponen los intereses de las comunidades ejidales (en el caso de México) frente a las compañías mineras, conjugándose cuestiones como son el abastecimiento de agua, la degradación medioambiental, la productividad de los cultivos y las explotaciones mineras, junto a la contratación de mano de obra autóctona; y donde la escasez hídrica, provocada por causas naturales o antropogénicas, puede constituir un multiplicador de la conflictividad en las regiones afectadas.

La relación entre las compañías mineras y las comunidades agrícolas pone de manifiesto una situación desigual en favor de las empresas mineras, en detrimento de los campesinos, lo que hasta la fecha no se ha atendido claramente mediante una política pública que tome en cuenta, con responsabilidad, estas disparidades para resolver los conflictos de manera que se encuentren soluciones equitativas.

Hemos mostrado que los beneficios obtenidos por la actividad minera de plata son muy superiores a los beneficios producidos por el cultivo de tres productos alimenticios básicos (arroz, frijoles y maíz). Adicionalmente, se ha visto como el consumo de agua por el sector agrícola es muy superior al del sector minero; sin embargo, esto no puede ser motivo para que se de preferencia a una actividad, sin respeto frente a otra, y menos, cuando de ello se infiere el uso de un bien vital como es el agua. Además, en la medida en que no se ofrezcan garantías, a través de políticas públicas, de alternativas viables a los modos de vida y subsistencia de las poblaciones agrícolas afectadas, la jerarquización en los usos del agua, y la privación de este bien a una comunidad representa un supuesto de violencia estructural; y como hemos podido observar en la comunidad Bajío de La Tesorera, en este tipo de diálogos se produce la desconfianza por parte de los miembros de la comunidad hacia los organismos estatales, al no considerarlos imparciales, y en todo caso no garantes de sus derechos y necesidades.

En estos casos, es innegable la existencia de la violencia ligada a razones económicas, políticas y sociales, con independencia de su visibilidad tangible a través de manifestaciones $\mathrm{o}$ ataques físicos a las autoridades. Es por este motivo que creemos que debería extenderse la utilización de los MASC, tal y como se reconoce para la Cuenca del Altiplano, para que fuesen de aplicación igualmente en la Cuenca de Nazas Aguanaval y la Cuenca de Río Santiago, y en todos aquellos supuestos en los que también pudieran ser de aplicación, a fin de que la sociedad sienta confianza en la resolución de sus conflictos, al poder formar parte de los procesos y ser asistidos por terceros imparciales que empoderen a las partes débiles en su búsqueda de equidad.

A pesar de la propuesta anterior, atendiendo a lo detectado por la iniciativa Justicia Cotidiana, advertimos que con independencia del esfuerzo en la labor desarrollada desde el gobierno y la academia por dar a conocer los MASC entre la población civil, este es aún insuficiente, necesitándose la estructuración de un esquema gubernamental de concienciación y difusión de estos métodos, junto con otras de sensibilización en torno a la paz y el respeto de los elementos mínimos de convivencia, a fin de garantizar la seguridad con que ha de contar todo Estado democrático consolidado.

Así mismo, otro problema detectado es la desconfianza de la población hacia la Justicia tradicional. Esta situación únicamente puede revertirse a través de la transparencia y el obrar diligente de las instituciones y los servidores públicos, junto con su mejor acceso y disponibilidad en aquellos escenarios en que por su especial situación geográfica, pueda dar lugar a una situación de abandono institucional para los habitantes de estas regiones. Por estas razones, sería adecuado estudiar, planificar y poner en práctica mecanismos de justicia itinerante, atendiendo a las recomendaciones dadas por la iniciativa de Justicia Cotidiana, junto con una estrategia de política pública clara a nivel federal, que permita la coordinación en la resolución de estos problemas en toda la República.

Por su parte Perú, siguiendo la senda y los resultados obtenidos por el Estado mexicano, cuenta con un modelo a seguir en la aplicación de los MASC, con objeto de reducir la conflictividad social y mejorar la calidad de vida de sus ciudadanos; a la par que logre una gobernanza de los poderes públicos más efectiva, sin olvidar que aún queda una gran labor por hacer al respecto, como sería la 
Alternative justice mechanisms as a daily justice policy in the face of the conflict over the use of water in Mexico and its potential application in Peru

reforma constitucional para dar cabida a estos mecanismos.

\section{FUENTES DE INFORMACIÓN}

\section{Fuentes bibliográficas}

Centro Internacional de Investigación e Información para la Paz. (2000). El estado de la paz y la evolución de las violencias: la situación de América Latina. Montevideo, Uruguay: Ediciones Trilce.

Comisión Nacional del Agua. (octubre de 2016). Estadísticas del Agua en México 2016. Ciudad de México, México: Secretaría del Medio Ambiente y Recursos Naturales.

Defensoría del Pueblo. (2015). Conflictos Sociales y recursos hídricos. Lima, Perú: Defensoría del Pueblo.

Gobierno del Estado de Zacatecas. (2015). Programa hídrico estatal - visión 2030 Zacatecas. 23: abril.

Rivera Hernández, P., \& Tamez González, G. (2015). La mediación como mecanismo alternativo de solución de conflictos en las relaciones internacionales. En A. Hernández Paz, \& A. Sánchez García, Solución de conflictos en las relaciones comerciales internacionales (págs. 224-239). México, D.F., México: Rechtikal S.A. de C.V.

Wright, C. (2015). Desde el conflicto al diálogo en la gestión de las protestas sociales. En P. Cabello Tijerina, \& J. Moreno Aragón, Diversas miradas, un mismo sentir: comunicación, ciudadanía y paz como retos del siglo XXI (págs. 135-146). México, D.F., México: Plaza y Valdés, S.A de C.V.

\section{Fuentes hemerográficas}

Navas Acevedo, R. E., García, M., \& Rodríguez Hernández, H. (2016). Cambio Climático, crisis Socioeconómica y supervivencia. Ojeando la agenda(42), 1-18.

Meléndez, C., \& León, C. (2009). Perú 2008: el juego de ajedrez de la gobernabilidad en partidas simultáneas. Revista de Ciencia Política, 29(2), 591-609.

\section{Fuentes electrónicas}

Atencio, R. (18 de marzo de 2014). Alrededor de 2500 mineras son informales en Junín. Diario Correo. Obtenido de http://diariocorreo. pe/ciudad/alrededor-de-2500-mineras-soninformales-en-44548/

Autoridad Nacional del Agua. (2015). Huella hídrica del Perú. Sector agropecuario. Autoridad Nacional del Agua.

Autoridad Nacional del Agua. (23 de enero de 2017). Nosotros. Obtenido de Autoridad Nacional del Agua (ANA): http://www.ana. gob.pe/nosotros/la-autoridad/nosotros

Autoridad Nacional del Agua. (1 de enero de 2017). Tribunal Nacional de resolución de controversias hídricas. Obtenido de Autoridad Nacional del Agua (ANA): http://www.ana. gob.pe/organizacion-funciones/tribunalnacional-resolucion-controversias-hidricas

CartoCritica. (26 de enero de 2016). Concesiones de agua para las mineras. Obtenido de CartoCritica: http://www. cartocritica.org. $\mathrm{mx} / 2016 /$ concesiones-deagua-para-las-mineras/

Central Intelligence Agency. (1 de agosto de 2017a). The World Factbook - Mexico. Obtenido de Central Intelligence Agency: https://www.cia.gov/library/publications/theworld-factbook/geos/mx.html

Central Intelligent Agency. (1 de agosto de 2017b). The World Factbook - Perú. Obtenido de Central Intelligent Agency: https://www.cia. gov/library/publications/the-world-factbook/ geos/pe.html

Centro de Investigación y Docencia Económicas. (2015). Informe de resultados de los Foros de Justicia Cotidiana. México, D.F.: Centro de Investigación y Docencia Económicas. Obtenido de https://imco.org. $\mathrm{mx} / \mathrm{wp}$-content/uploads/2015/04/Documento_ JusticiaCotidiana_.pdf

Centro Internacional de Investigación e Información para la Paz. (2000). El estado de la paz y la evolución de las violencias: la situación de América Latina. Montevideo: Edicioones Trilce. 
Cervera Fantoni, Á. (2003). Envase y embalaje (la venta silenciosa). Madrid: ESIC Editorial.

Comisión Interamericana de Derechos Humanos. (2007). Acceso a la justicia como garantía de los derechos económicos, sociales $y$ culturale. Estudio de estantares fijados por el Sistema Interamericano de Derechos Humanos. OEA.

Comisión Nacional del Agua. (7 de octubre de 2011). Reglas Generales de Integración, Organización y Funcionamiento del Consejo de Cuenca de Río Santiago. Obtenido de Comisión Nacional del Agua: http:// www.conagua.gob.mx/CONAGUA07/ contenido/documentos/13\%20Reglas $\% 20$ R\%C3\%ADo\%20Santiago.pdf

Comisión Nacional del Agua. (7 de octubre de 2011). Reglas Generales de Integración, Organización y Funcionamiento del Consejo de Cuenca de Río Santiago. Obtenido de Comisión Nacional del Agua (CONAGUA): http://www.conagua.gob.mx/CONAGUA07/ contenido/documentos/13\%20Reglas $\% 20$ R\%C3\%ADo\%20Santiago.pdf

Comisión Nacional del Agua. (13 de mayo de 2014). Reglas Generales de Integración, Organización y Funcionamiento del Consejo de Cuenca de Nazas Aguanaval. Obtenido de Comisión Nacional del Agua: http://www. conagua.gob.mx/CONAGUA07/contenido/ documentos $/ 10 \% 20$ Reglas $\% 20$ Nazas $\% 20$ Aguanaval.pdf

Comisión Nacional del Agua. (13 de mayo de 2014). Reglas Generales de Integración, Organización y Funcionamiento del Consejo de Cuenca del Altiplano. Obtenido de CONAGUA: http://www.conagua.gob.mx/ CONAGUA07/contenido/documentos/11\%20 Reglas\%20Altiplano.pdf

Comisión Nacional del Agua. (octubre de 2016). Estadísticas del Agua en México 2016. Ciudad de México: Secretaría del Medio Ambiente y Recursos Naturales.

Comisión Nacional del Agua. (2 de febrero de 2017). Atlas del agua en México 2016. Obtenido de Secretaría de Medio Ambiente y Recursos Naturales: http://201.116.60.25/ publicaciones/AAM_2016.pdf
Comisión Nacional del Agua. (6 de enero de 2017). Precipitación a nivel nacional y por entidad federativa 2016. Obtenido de http://smn.cna.gob.mx/ tools/DATA/Climatolog\%C3\% A Da/ Pron $\%$ C3\%B3stico\%20clim\%C3\%A1 tico/ Temperatura\%20y\%20Lluvia/PREC/2016.pdf

Comisión Nacional del Agua. (23 de marzo de 2018). Comisión Nacional del Agua - ¿qué hacemos? Obtenido de gob.mx: https://www. gob.mx/conagua/que-hacemos

Convención de las Naciones Unidas para la Lucha contra la desertificación. (2014). La desertificación: esa invisible línea de frente. Bonn: UNCCD. Obtenido de http:// www.unccd.int/Lists/SiteDocumentLibrary/ Publications/Final_Security_SPA\%2018_ march_14\%20low\%20res.pdf

CooperAccion. (2016). Noveno informe cartográfico sobre concesiones mineras en Perú. Lima: CooperAccion. Obtenido de http:// cooperaccion.org.pe/main/images/Archivos/ Informedeconcesionesminerasmayo2016.pdf

Crespo, G. (29 de enero de 2016). Extrae minera agua para el campo. NTR Zacatecas. Obtenido de http://ntrzacatecas.com/2016/01/29/extraeminera-agua-para-el-campo/

Defensoría del Pueblo. (13 de julio de 2015). ¿Sabes qué es un pasivo ambiental y cómo puede afectarnos? Obtenido de Blog de la Defensoría del Pueblo: http://www.defensoria. gob.pe/blog/sabes-que-es-un-pasivoambiental-y-como-puede-afectarnos/

Defensoría del Pueblo. (2015). Conflictos Sociales y recursos hídricos. Lima: Defensoría del Pueblo.

El País. (19 de septiembre de 2008). El oro y la plata se disparan en Bolsa como valores refugio. Obtenido de El País: https://elpais.com/diario/2008/09/19/ economia/1221775207_850215.html

Fetzek, S. (2009). Climate-related impacts on national security in Mexico and Central America. Londres: RUSI. Obtenido de https:// rusi.org/system/files/Mexico_CC_Text_-_ English.pdf 
el conflicto por el uso del agua en México y su potencial aplicación en el Perú

Alternative justice mechanisms as a daily justice policy in the face of the conflict over the use of water in Mexico and its potential application in Peru

Fondo para la Comunicación y la Educación Ambiental. (4 de octubre de 2017). Los retos del uso agrícola del agua. Obtenido de Agua. org.mx: https://agua.org.mx/editoriales/losretos-del-uso-agricola-del-agua/

Gobierno del Estado de Zacatecas. (25 de octubre de 2013). Plan Estatal de Desarrollo 2011-2016. Obtenido de Secretaria de Gobernación - Unidad General de Asuntos Jurídicos: http://www.ordenjuridico.gob.mx/ Documentos/Estatal/Zacatecas/wo86958.pdf

Gobierno del Estado de Zacatecas. (2015). Programa hídrico estatal - visión 2030 Zacatecas. 23: abril.

Gobierno Regional Junín. (2017). Junín: Compendio estadístico agropecuario 19972016. Huancayo: Dirección Regional de Agricultura de Junín.

Gorjón Gómez, F. (2015). De la instrumentalización a la cientificidad de la mediación y de los métodos alternos de solución de conflictos. En F. J. Gorjón Gómez, \& J. Pesqueira, La ciencia de la mediación (págs. 13-36). México, D.F.: Tirant Lo Blanch México.

Gorjón Gómez, F., \& Steele Garza, J. (2016). Métodos alternativos de solución de conflictos. Ciudad de México: Oxford University Press.

Guzmán López, F. (2016a). Economía política del despojo territorial. Megaminería a cielo abierto en Zacatecas bajo el capital global 1982-2014. Tesis doctoral. Universidad Autónoma de Zacatecas. Obtenido de http://ricaxcan.uaz.edu.mx:8080/bitstream/ handle/20.500.11845/79

Guzmán López, F. (2016b). Impactos ambientales causados por megaproyectos de minería a cielo abierto en el estado de Zacatecas, México. Revista de Geografía Agrícola(56), 109-128. doi:10.5154/r.rga.2016.57.010

Huntjens, P., \& Nachbar, K. (2015). Climate change as a Threat Multiplier for Human Disaster and Conflict. The Hague, Netherlands: The Hague Institute for Global Justice. Obtenido de http://www. thehagueinstituteforglobaljustice.org/wpcontent/uploads/2015/10/working-Paper-9climate-change-threat-multiplier.pdf
Instituto Nacional de Estadística e Informática. (2015). Anuario de Estadísticas Ambientales 2015. Lima: Instituto Nacional de Estadística e Informática (INEI). Obtenido de https:// www.inei.gob.pe/media/MenuRecursivo/ publicaciones_digitales/Est/Lib1342/

Instituto Nacional de Estadística e Informática. (2015). Estado de la población peruana. Lima: Instituto Nacional de Estadística e Informática (INE). Obtenido de http://www.inei.gob. $\mathrm{pe} / \mathrm{media} /$ MenuRecursivo/publicaciones digitales/Est/Lib1251/Libro.pdf

Instituto Nacional de Estadística e Informática. (2017). Estadísticas Ambientales. Lima: Instituto Nacional de Estadística e Informática (INEI). Obtenido de https://www.inei.gob.pe/ media/MenuRecursivo/boletines/07-informetecnico-n07_estadisticas-ambientalesjun2017.pdf

Instituto Nacional de Estadística e Informática. (14 de julio de 2017). Temperatura promedio anual, según departamento, 2003-2015. Obtenido de Instituto Nacional de Estadística e Informática (INE): https://www.inei.gob.pe/ estadisticas/indice-tematico/climate/

Justicia Cotidiana. (2016). Diálogos por la Justicia Cotidiana: diagnósticos, conjuntos y soluciones. México, D.F.: Justicia Cotidiana. Obtenido de https://www.gob.mx/cms/ uploads/attachment/file/79028/Di_logos Justicia_Cotidiana.pdf

Kimmelman, M. (17 de febrero de 2017). Ciudad de México, al borde de una crisis por el agua. The New York Times. Obtenido de https:// www.nytimes.com/es/interactive/ciudad-demexico-al-borde-de-una-crisis-por-el-agua/

López Ga., M. (26 de mayo de 2017). “iEl agua vale más que el oro!" Cajamarca contra la minería en Colombia. Obtenido de Laboratorio de Estudios sobre Empresas Transnacionales: http://let.iiec.unam.mx/node/1373

Lysaght, P. (21 de marzo de 2016). 5 realidades sobre el agua y el cambio climático. Obtenido de UNICEF: https://blogs.unicef.org/es/ blog/5-realidades-sobre-el-cambio-climatico/

Massachusetts Institute of Technology. (3 de abril de 2013). Environmental Risks of Mining, Mission 2016: The Future of Strategic Natural Resources. Obtenido de Massachusetts 
Institute of Technology (MIT): http://web. mit.edu/12.000/www/m2016/finalwebsite/ problems/mining.html

Meléndez, C., \& León, C. (2009). Perú 2008: el juego de ajedrez de la gobernabilidad en partidas simultáneas. Revista de Ciencia Política, 29(2), 591-609.

Ministerio de Agricultura y Riego de Perú. (2015). Ministerio de Agricultura y Riego de Perú. Obtenido de Ministerio de Agricultura y Riego de Perú: http://www.minagri.gob.pe/ portal/objetivos/42-sector-agrario/recursoagua/324-vertientes-y-disponibilidad-de-agua

Morales, R. (16 de abril de 2015). Fresnillo PLC encabeza récord global de plata. El Economista. Obtenido de http://eleconomista. com.mx/industrias/2015/04/16/fresnillo-plcencabeza-record-global-plata

Navas Acevedo, R. E., García, M., \& Rodríguez Hernández, H. (2016). Cambio Climático, crisis Socioeconómica y supervivencia. Ojeando la agenda(42), 1-18.

NTR Zacatecas. (22 de septiembre de 2016). Organizan frente para vigilar a minera. NTR Zacatecas. Obtenido de http://ntrzacatecas. com/2016/09/22/organizan-frente-paravigilar-a-minera/

Organización de las Naciones Unidas para la Educación, la Ciencia y la Cultura. (25 de mayo de 2013). Basin Water Allocation Planning: principles, procedures and approaches for Basic Allocation Planning. Obtenido de UNESCO: http://unesdoc.unesco. org/images/0022/002208/220875e.pdf

Proyecto ZEE Junín. (agosto de 2015). Mapa de Cuencas de la Región de Junín. Obtenido de SIAR Junín: http://siar.regionjunin.gob.pe/ mapas/mapa-cuencas-region-junin

Ramírez, M. F., \& Yepes, M. J. (2011). Geopolítica de los recursos estratégicos: conflictos por agua en América Latina. Revista de Relaciones Internacionales, Estrategia y Seguridad, 149-165. Obtenido de http://www. redalyc.org/pdf/927/92722560006.pdf

Razeto M., L. (2008). Un análisis alternativo de la actual crisis económica global y sus vías de superación. Revista de la Universidad Bolivariana, 7(21), 181-199. doi:http://dx.doi. org/10.4067/S0718-65682008000200010
Registro Agrario Nacional. (31 de diciembre de 2014). Núcleos agrarios a nivel nacional. Obtenido de Registro Agrario Nacional: http:// www.ran.gob.mx/ran/pano_agr-map/imgs/ nucleos/nucleos-agrarios_Page_01.pdf

Registro Agrario Nacional. (31 de diciembre de 2014). Núcleos agrarios en Zacatecas. Obtenido de Registro Agrario Nacional: http:// www.ran.gob.mx/ran/pano_agr-map/imgs/ nucleos/nucleos-agrarios_Page_33.pdf

Ríos, A. (6 de agosto de 2016). Sigue en la impunidad minera Saucito tras derrame de jales provocado en Fresnillo. La Jornada. Obtenido de http://jz.mx/2016/08/06/sigue-laimpunidad-minera-saucito-tras-derrame-jalesprovocado-fresnillo/

Rivera Hernández, P., \& Tamez González, G. (2015). La mediación como mecanismo alternativo de solución de conflictos en las relaciones internacionales. En A. Hernández Paz, \& A. Sánchez García, Solución de conflictos en las relaciones comerciales internacionales (págs. 224-239). México, D.F.: Rechtikal S.A. de C.V.

Secretaría Ejecutiva del Acuerdo Nacional. (16 de agosto de 2012). Política del Estado sobre los Recursos Hídricos - Acuerdo Nacional. Lima: Secretaría Ejecutiva del Acuerdo Nacional. Obtenido de Autoridad Nacional del Agua (ANA): http://www.ana.gob.pe/ sites/default/files/politica_de_recursos_ hidricos_33_documento.pdf

Servicio de Información Agroalimentaria y Pesquera. (9 de enero de 2017). Anuario Estadístico de la Producción Agrícola. Obtenido de gob.mx: http://nube.siap.gob.mx/ cierre_agricola/

Servicio Geológico Mexicano. (2016). Panorama minero del Estado de Zacatecas. Zacatecas: Servicio Geológico Mexicano. Obtenido de http://www.sgm.gob.mx/pdfs/ ZACATECAS.pdf

Shamir, Y. (2003). Alternative Dispute Resolution Approaches and their Application. UNESCO. Obtenido de http://unesdoc.unesco. org/images/0013/001332/133287e.pdf 
Alternative justice mechanisms as a daily justice policy in the face of the conflict over the use of water in Mexico and its potential application in Peru

Sociedad Nacional de minería, petróleo y energía. (2017). Reporte estadístico minero energético 2016. Lima: Sociedad Nacional de minería, petróleo y energía. Obtenido de http:// www.snmpe.org.pe/informes-y-publicaciones/ reporte-estadistico-mineroenergetico/4548ano-2016-fecha-de-publicacion-abril-2017. html

United Nations. (2013). International Annaul UN-Water, Zaragoza Conference 2012/2013. Obtenido de United Nations: http://www.un.org/waterforlifedecade/water cooperation_2013/mediation_and_dispute resolution.shtml

Valadez Rodríguez, A. (5 de octubre de 2016a). Ejidatarios mantienen 〈toma〉 de mina de oro en Zacatecas. La Jornada. Obtenido de http:// www.jornada.unam.mx/ultimas/2016/10/05/ ejidatarios-mantienen-toma-de-mina-de-oroen-zacatecas

Valadez Rodríguez, A. (12 de julio de 2017a). Campesinos levantan bloqueo contra minera en Zacatecas. La Jornada. Obtenido de http:// www.jornada.unam.mx/ultimas/2017/07/12/ campesinos-levantan-bloqueo-contra-mineraen-zacatecas

Valadez Rodríguez, A. (12 de julio de 2017b). Bloquean paso a mina inglesa en Zacatecas; demandan agua. La Jornada. Obtenido de http://www.jornada.unam.mx/2017/07/12/ estados/025n1est
Valadez, A. (9 de octubre de 2016b). Afectados por la mina Peñasquito concluyen protesta de 12 días. La jornada. Obtenido de http://www.jornada.unam.mx/2016/10/09/ estados/024n1est

Wright, C. (2015). Desde el conflicto al diálogo en la gestión de las protestas sociales. En P. Cabello Tijerina, \& J. Moreno Aragón, Diversas miradas, un mismo sentir: comunicación, ciudadanía y paz como retos del siglo XXI (págs. 135-146). México, D.F.: Plaza y Valdés, S.A de C.V.

Zacarías, S. (10 de diciembre de 2015). Minera de Bailleres contaminó comunidad Saucito del Poleo. La Jornada. Obtenido de http://1jz.mx/2015/12/10/minera-de-baillerescontamino-comunidad-saucito-del-poleo/

Zonificación Ecológica y Económica de la Región de Junín (ZEE). (18 de mayo de 2016). Zonificación Ecológica y Económica Memoria descriptiva del estudio hidrológico $y$ de cuencas del departamento de Jnín a escala 1:100000. Obtenido de SIAR Junín: http://siar.regionjunin.gob.pe/sites/default/ files/archivos/public/docs/medio_fisico_memoria_descriptiva_hidrologia.pdf 